\title{
Fluorescent bioaerosol particle, molecular tracer, and fungal spore concentrations during dry and rainy periods in a semi-arid forest
}

\author{
Marie Ila Gosselin ${ }^{1,2}$, Chathurika M. Rathnayake ${ }^{3}$, Ian Crawford ${ }^{4}$ Christopher Pöhlker $^{2}$, \\ Janine Fröhlich-Nowoisky ${ }^{2}$, Beatrice Schmer ${ }^{2}$, Viviane R. Després ${ }^{5}$, Guenter Engling ${ }^{6}$, Martin Gallagher $^{4}$, \\ Elizabeth Stone $^{3}$, Ulrich Pöschl ${ }^{2}$, and J. Alex Huffman ${ }^{1}$ \\ ${ }^{1}$ Department of Chemistry and Biochemistry, University of Denver, Denver, CO, USA \\ ${ }^{2}$ Max Planck Institute for Chemistry, Multiphase Chemistry and Biogeochemistry Departments, Mainz, Germany \\ ${ }^{3}$ Department of Chemistry, University of Iowa, Iowa City, IA, USA \\ ${ }^{4}$ Centre for Atmospheric Science, SEAES, University of Manchester, Manchester, UK \\ ${ }^{5}$ Institute of General Botany, Johannes Gutenberg University, Mainz, Germany \\ ${ }^{6}$ Division of Atmospheric Sciences, Desert Research Institute, Reno, NV, USA
}

Correspondence to: J. Alex Huffman (alex.huffman@du.edu)

Received: 16 August 2016 - Published in Atmos. Chem. Phys. Discuss.: 7 September 2016

Revised: 4 November 2016 - Accepted: 7 November 2016 - Published: 8 December 2016

\begin{abstract}
Bioaerosols pose risks to human health and agriculture and may influence the evolution of mixed-phase clouds and the hydrological cycle on local and regional scales. The availability and reliability of methods and data on the abundance and properties of atmospheric bioaerosols, however, are rather limited. Here we analyze and compare data from different real-time ultraviolet laser/lightinduced fluorescence (UV-LIF) instruments with results from a culture-based spore sampler and offline molecular tracers for airborne fungal spores in a semi-arid forest in the southern Rocky Mountains of Colorado. Commercial UVAPS (ultraviolet aerodynamic particle sizer) and WIBS-3 (wideband integrated bioaerosol sensor, version 3) instruments with different excitation and emission wavelengths were utilized to measure fluorescent aerosol particles (FAPs) during both dry weather conditions and periods heavily influenced by rain. Seven molecular tracers of bioaerosols were quantified by analysis of total suspended particle (TSP) high-volume filter samples using a high-performance anionexchange chromatography system with pulsed amperometric detection (HPAEC-PAD). From the same measurement campaign, Huffman et al. (2013) previously reported dramatic increases in total and fluorescent particle concentrations during and immediately after rainfall and also showed a strong relationship between the concentrations of FAPs and ice nuclei (Huffman et al., 2013; Prenni et al., 2013). Here we investi-
\end{abstract}

gate molecular tracers and show that during rainy periods the atmospheric concentrations of arabitol $\left(35.2 \pm 10.5 \mathrm{ng} \mathrm{m}^{-3}\right)$ and mannitol $\left(44.9 \pm 13.8 \mathrm{ng} \mathrm{m}^{-3}\right)$ were $3-4$ times higher than during dry periods. During and after rain, the correlations between FAP and tracer mass concentrations were also significantly improved. Fungal spore number concentrations on the order of $10^{4} \mathrm{~m}^{-3}$, accounting for $2-5 \%$ of TSP mass during dry periods and $17-23 \%$ during rainy periods, were obtained from scaling the tracer measurements and from multiple analysis methods applied to the UV-LIF data. Endotoxin concentrations were also enhanced during rainy periods, but showed no correlation with FAP concentrations. Average mass concentrations of erythritol, levoglucosan, glucose, and $(1 \rightarrow 3)$ - $\beta$-D-glucan in TSP samples are reported separately for dry and rainy weather conditions. Overall, the results indicate that UV-LIF measurements can be used to infer fungal spore concentrations, but substantial development of instrumental and data analysis methods appears to be required for improved quantification. 


\section{Introduction}

Primary biological aerosols particles (PBAPs) are of keen interest within the scientific community, partially because methods for their quantification and characterization are advancing rapidly (Huffman and Santarpia, 2017; Sodeau and O'Connor, 2016). The term PBAPs, or equivalently bioaerosols, generally comprises several classes of airborne biological particles including viruses, bacteria, fungal spores, pollen, and their fragments (Després et al., 2012; FröhlichNowoisky et al., 2016). Fungal spores are of particular atmospheric interest because they can cause a variety of deleterious health effects in humans, animals, and agriculture, and it has been shown that they can represent a significant fraction of total organic aerosol emissions (Deguillaume et al., 2008; Gilardoni et al., 2011; Madelin, 1994), especially in tropical regions (Elbert et al., 2007; Huffman et al., 2012; Pöschl et al., 2010; Zhang et al., 2010). Current estimates of the atmospheric concentration of fungal spores range from $10^{0}$ to more than $10^{4} \mathrm{~m}^{-3}$ (Frankland and Gregory, 1973; Gregory and Sreeramulu, 1958; Heald and Spracklen, 2009; Hummel et al., 2015; Sesartic and Dallafior, 2011). Fungal spores may also impact the hydrological cycle as giant cloud condensation nuclei or as ice nuclei (Haga et al., 2013; Morris et al., 2013; Sesartic et al., 2013). Additionally, several classes of bioaerosols and their constituent components, such as $(1 \rightarrow 3)-\beta$-D-glucan and endotoxins, have been implicated in respiratory distress and allergies (Burger, 1990; Douwes et al., 2003; Laumbach and Kipen, 2005; Linneberg, 2011; Pöschl and Shiraiwa, 2015). For example, asthma and allergies have shown notable increases during thunderstorms due to elevated bioaerosol concentrations (Taylor and Jonsson, 2004) especially when attributed to fungal spores (Allitt, 2000; Dales et al., 2003).

Molecular tracers have long been utilized as a means of aerosol source tracking (Schauer et al., 1996; Simoneit and Mazurek, 1989; Simoneit et al., 2004). In recent years, analysis of molecular tracers has been utilized for the quantification of PBAPs in atmospheric samples and has been compared, for example, with results from microscopy (Bauer et al., 2008a) and culture samples (Chow et al., 2015b; Womiloju et al., 2003). Three organic molecules have been predominately utilized as unique tracers of fungal spores: ergosterol, mannitol, and arabitol. The majority of atmospherically relevant fungal spores are released by active wetdischarge processes common in Ascomycota and Basidiomycota, meaning that the fungal organism actively ejects spores at a time most advantageous for the spore dispersal and germination processes, often when relative humidity (RH) is high (Ingold, 1971). While there are several mechanisms of active spore emission (e.g., Buller's drop (Buller, 1909) and osmotic pressure canons (Ingold, 1971)), they each involve the secretion of fluid containing hygroscopic compounds, such as arabitol, mannitol, potassium and chloride ions, as well as other solutes (Elbert et al., 2007), released near the site of spore growth. When the spores are ejected, some of the fluid adheres to the spores and becomes aerosolized. Several of these secreted compounds are thought to enter the atmosphere linked uniquely with spore emission processes, and so these tracers have been used to estimate atmospheric concentrations of fungal spores. Arabitol and mannitol are both sugar alcohols (polyols) that serve as energy stores for the spore (Feofilova, 2001). Arabitol is unique to fungal spores and lichen, while mannitol is present in fungal spores, lichen, algae, and higher plants (Lewis and Smith, 1967). Ergosterol is found within the cell membranes of fungal spores (Weete, 1973) and has been used as an ambient fungal spore tracer (Di Filippo et al., 2013; Miller and Young, 1997). Comparing the seasonal trends of arabitol and mannitol with ergosterol, Burshtein et al. (2011) showed positive correlations between arabitol or mannitol and ergosterol only in the spring and autumn, suggesting that the source of these polyols is unlikely to be solely fungal in origin or that the amount of each compound emitted varies considerably between species type and season. While ergosterol has been directly linked to fungal spores in the air, ergosterol is prone to photochemical degradation and is difficult to analyze and quantify directly. Quantification of ergosterol typically requires chemical derivatization by silylation before analysis via gas chromatography (Axelsson et al., 1995; Burshtein et al., 2011; Lau et al., 2006). In contrast, analysis of sugar alcohols by ion chromatography involves fewer steps and has been successfully applied to monitor seasonal variations of atmospheric aerosol concentration at a number of sites (Bauer et al., 2008a; Caseiro et al., 2007; Yang et al., 2012; Yttri et al., 2011a; Zhang et al., 2010, 2015) including $\mathrm{pg} \mathrm{m}^{-3}$ (picograms per cubic meter) levels in the Antarctic (Barbaro et al., 2015). By measuring spore count and tracer concentration in parallel at one urban and two suburban sites in Vienna, Austria, Bauer et al. (2008a) estimated the amount of each tracer per fungal spore emitted. Potassium ions have also been linked to emission of biogenic aerosol (Pöhlker et al., 2012b) and are co-emitted with fungal spores; however, application of potassium as a fungal tracer is uncommon because it is predominantly associated with biomass burning (Andreae and Crutzen, 1997). Additionally, $(1 \rightarrow 3)-\beta$ D-glucan (fungal spores and pollen) and endotoxins (gramnegative bacteria) have also been widely used to measure other bioaerosols (Andreae and Crutzen, 1997; Cheng et al., 2012; Rathnayake et al., 2016b; Stone and Clarke, 1992).

The direct detection of PBAPs has historically been limited to analysis techniques that require culturing or microscopy of the samples. These systems are time-consuming, costly, and often substantially under-count biological particles by an order of magnitude or more (Gonçalves et al., 2010; Pyrri and Kapsanaki-Gotsi, 2007). The sampling methods associated with these measurements also offer relatively low time resolution and low particle size resolution. Recently, techniques utilizing ultraviolet laser/light-induced fluorescence (UV-LIF) for the real-time detection of PBAPs 
have been developed and are being utilized by the atmospheric community for bioaerosol detection. Thus far, the most widely applied LIF instruments for ambient PBAP detection have been the ultraviolet aerodynamic particle sizer (UV-APS; TSI Inc. Model 3314, St. Paul, MN, USA) and the wideband integrated bioaerosol sensor (WIBS; University of Hertfordshire, Hertfordshire, UK, now licensed to Droplet Measurement Technologies, Boulder, CO, USA). Both of these commercially available instruments can provide information in real-time about particle size and fluorescence properties of supermicron atmospheric aerosols. Characterization and co-deployment of these instruments over the past 10 years has expanded the knowledge base regarding how to analyze and utilize the information provided from these instruments (Crawford et al., 2015; Healy et al., 2014; Hernandez et al., 2016; Huffman et al., 2013; Perring et al., 2015; Pöhlker et al., 2012a, 2013; Ruske et al., 2016), though the interpretation of UV-LIF results from individual particles is complicated by interfering material that is not biological in nature (Gabey et al., 2010; Huffman et al., 2012; Lee et al., 2010; Saari et al., 2013; Toprak and Schnaiter, 2013).

Here we present analysis of atmospheric concentrations of arabitol and mannitol in relation to results from realtime, ambient particle measurements reported by UV-APS and WIBS. We interrogate these relationships as they pertain to rain conditions (rainfall and $\mathrm{RH}$ ) that have previously been shown to increase the concentrations of fluorescent aerosols and ice nuclei (Crawford et al., 2014; Huffman et al., 2013; Prenni et al., 2013; Schumacher et al., 2013; Yue et al., 2016). Active wet discharge of ascospores and basidiospores has frequently been reported to correspond with increased $\mathrm{RH}$ (Elbert et al., 2007), and fungal spore concentration has also been shown to increase after rain events (e.g., Jones and Harrison, 2004). Here we estimate airborne fungal concentrations in a semi-arid forest environment utilizing a combination of real-time fluorescence methods, molecular fungal tracer methods, and direct-to-agar sampling and culturing as parallel surrogates for spore analysis. This study of ambient aerosol represents the first quantitative comparison of realtime aerosol UV-LIF instruments with molecular tracers or culturing.

\section{Methods}

\subsection{Sampling site}

Atmospheric sampling was conducted as a part of the BEACHON-RoMBAS (Bio-hydro-atmosphere interactions of Energy, Aerosols, Carbon, $\mathrm{H}_{2} \mathrm{O}$, Organics, and Nitrogen - Rocky Mountain Biogenic Aerosol Study) field campaign conducted at the Manitou Experimental Forest Observatory (MEFO) located $48 \mathrm{~km}$ northwest of Colorado Springs, Colorado $\left(39^{\circ} 06^{\prime} 0^{\prime \prime} \mathrm{N}, 105^{\circ} 5^{\prime} 03^{\prime \prime} \mathrm{W} ; 2370 \mathrm{~m}\right.$ elevation) (Ortega et al., 2014). The site is located in the cen- tral Rocky Mountains and is representative of the semiarid montane pine-forested regions of North America. During BEACHON-RoMBAS, a large, international team of researchers conducted an intensive set of measurements from 20 July to 23 August 2011. A summary of results from the campaign are published in the BEACHON campaign special issue of Atmospheric Chemistry and Physics (http:// www.atmos-chem-phys.net/special_issue247.html). All the data reported here were gathered from instruments and sensors located within a $<100 \mathrm{~m}$ radius (Fig. 1).

\subsection{Online fluorescent instruments}

UV-APS and WIBS-3 (model 3; University of Hertfordshire) instruments were operated continuously as a part of the study, and particle data were integrated to $5 \mathrm{~min}$ averages before further analysis. The UV-APS was operated under procedures defined in previous studies (Huffman et al., 2013; Schumacher et al., 2013). A total suspended particle (TSP) inlet head $\sim 5.5 \mathrm{~m}$ above the ground, mounted above the roof of a climate-controlled, metal trailer, was used to sample aerosol directed towards the UV-APS. Bends and horizontal stretches in the 0.75 inch tubing were minimized to reduce losses of large particles (Huffman et al., 2013). The UV-APS detects particles between 0.5 and $20 \mu \mathrm{m}$ and records aerodynamic particle diameter and integrated total fluorescence $(420-575 \mathrm{~nm})$ after pulsed excitation by a $355 \mathrm{~nm}$ laser (Hairston et al., 1997). Both UV-APS and WIBS instruments report information about particle number concentration, but it is instructive here to show results in particle mass for comparison between all techniques. Total particle number size distributions (irrespective of fluorescence properties) obtained from the UV-APS and WIBS were converted to mass distributions assuming spherical particles of unit particle mass density, unless otherwise stated, as a first approximation. Total particle concentration values (in $\mu \mathrm{g} \mathrm{m}^{-3}$ ) were obtained for each $5 \mathrm{~min}$ period by integrating over the size range $0.5-15 \mu \mathrm{m}$, and these mass concentration values were averaged over the length of the filter sampling periods. Uncertainty in mass concentration values reported here is influenced by assuming a single value for particle mass density and because of slight dissimilarities between size bins of the UV-APS and WIBS instruments at particle sizes above $10 \mu \mathrm{m}$ that dominate particle mass.

A WIBS-3 was used to continuously sample air at a site $\sim 50 \mathrm{~m}$ from the UV-APS trailer and $1.3 \mathrm{~m}$ above the ground. Briefly, the diameter of individual particles sampled by the WIBS is estimated by the intensity of the elastic side scatter from a continuous wave $635 \mathrm{~nm}$ diode laser and analyzed by a Mie scattering model (Foot et al., 2008; Kaye et al., 2005). Particles that pass through the diode laser activate two optically filtered Xenon flash lamps. The first lamp excites the particle at $280 \mathrm{~nm}$ and the second at $370 \mathrm{~nm}$. Emission from the $280 \mathrm{~nm}$ excitation is filtered separately for two photomultiplier tubes (PMTs), one which detects in a band at 


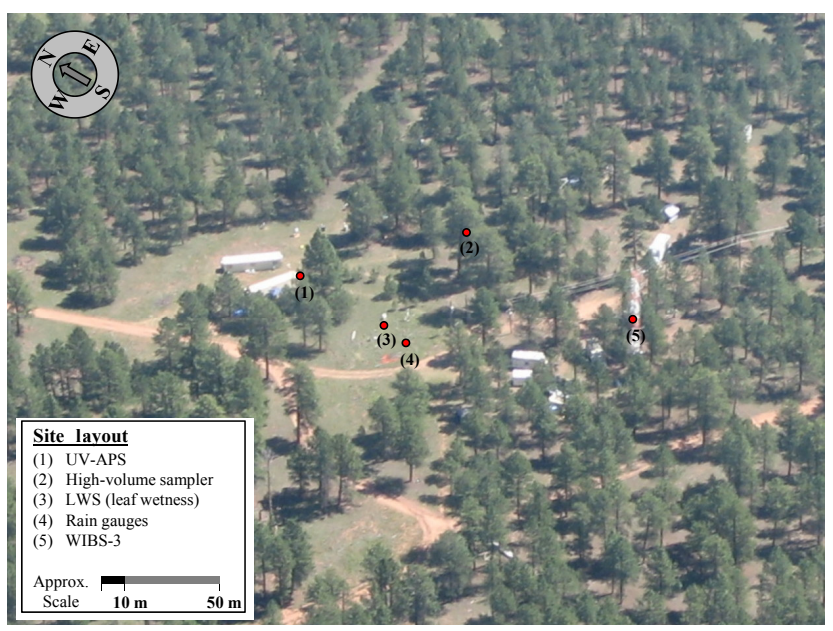

Figure 1. Aerial overview of BEACHON-RoMBAS field site at the Manitou Experimental Forest Observatory located northwest of Colorado Springs, CO. Locations of all instruments and sensors discussed here are marked and were located within a $50 \mathrm{~m}$ radius. Figure adapted from Fig. 1a of Huffman et al. (2013).

$320-400 \mathrm{~nm}$ and the other in a band at $410-650 \mathrm{~nm}$. These excitation and emission wavelengths result in a total of three channels of detection: $\lambda_{\text {ex }} 280 \mathrm{~nm}, \lambda_{\text {em }} 320-400 \mathrm{~nm}$ (FL1 or channel A); $\lambda_{\text {ex }} 280 \mathrm{~nm}, \lambda_{\mathrm{em}} 410-650 \mathrm{~nm}$ (FL2 or channel B); and $\lambda_{\text {ex }} 370 \mathrm{~nm}, \lambda_{\text {em }} 410-650 \mathrm{~nm}$ (FL3 or channel C) (Crawford et al., 2014). Individual particles are considered fluorescent here if they exceed fluorescent thresholds for any channel, as defined as the average of a "forced trigger" baseline plus 3 standard deviations (SD) of the baseline measurement (Gabey et al., 2010).

WIBS particle-type analysis is utilized to define types of particles that have specific spectral patterns. As defined by Perring et al. (2015), the three different fluorescent channels (FL1, FL2, and FL3) can be combined to produce seven unique fluorescent categories. Observed fluorescence in channel FL1 alone, but without any detectable fluorescence in channel FL2 or FL3, categorizes a particle as type A. Similarly, observed fluorescence in channels FL2 or FL3, but in no other channels, places a particle in the B or C categories, respectively. Combinations of fluorescence in these channels, such as a particle that exhibits fluorescence in both FL1 and FL2, categorizes a particle as type AB and so on for a possible seven particle types as summarized in Fig. S1 in the Supplement.

As a separate tool for particle categorization, the University of Manchester has recently developed and applied a hierarchical agglomerative cluster analysis tool for WIBS data, which they have previously applied to the BEACHONRoMBAS campaign (Crawford et al., 2014, 2015; Robinson et al., 2013). Here we utilize clusters derived from WIBS-3 data as described by Crawford et al. (2015). Cluster data presented here were analyzed with the open-source
Python package FastCluster (Müllner, 2013). Briefly, hierarchical agglomerative cluster analysis was applied to the entire data set and each fluorescent particle was uniquely clustered into one of four groups. Cluster 1, assigned by Crawford et al. (2015) as fungal spores, displayed a $1.5-2 \mu \mathrm{m}$ mode and a daily peak in the early morning that paralleled relative humidity (Schumacher et al., 2013). Clusters 2, 3, and 4 have strong, positive correlations with rainfall and exhibit size modes that peak at $<1.2 \mu \mathrm{m}$ and were initially described by Crawford et al. (2014) as bacterial particles. Here we have summed clusters $2-4$ to a single group referred to as $\mathrm{Cl}_{\text {Bact }}$, for simplicity when comparing with molecular tracers. It should be noted that assignment of name and origin (e.g., fungal spores or bacteria) to clusters is approximate and does not imply naming accuracy or particle homogeneity. Each cluster likely contains an unknown fraction of contaminating particles, but the clusters are beneficial to group particles more selectively than using fluorescent intensity alone. For more details see Robinson et al. (2013) and Crawford et al. (2015).

The WIBS-3 utilized here has since been superseded by the WIBS-4 (Univ. Hertfordshire, UK) and WIBS-4A (Droplet Measurement Technologies, Boulder, CO, USA). One important difference between the models is that the optical chamber design and filters of the WIBS-4 models were updated to enhance the overall sensitivity of the instrument (Crawford et al., 2014). Additionally, slight differences in detector gain between models and individual units can impact the relative sensitivity of the fluorescence channels. This may result in differences in fluorescent channel intensity between instrument models, as will be discussed later.

\subsection{High-volume sampler}

Total suspended particle samples were collected for molecular tracer and molecular genetic analyses using a highvolume sampler (Digitel DHA-80) drawing $1000 \mathrm{~L} \mathrm{~min}^{-1}$ through $15 \mathrm{~cm}$ glass fiber filters (Macherey-Nagel $\mathrm{GmbH}$, Type MN 85/90, 406015, Düren, Germany) over a variety of sampling times ranging from 4 to $48 \mathrm{~h}$ (Supplement Table S1). The sampler was located $<50 \mathrm{~m}$ from each of the UV-LIF instruments described here, approximately between the WIBS-3 and UV-APS. Prior to sampling, all filters were baked at $500^{\circ} \mathrm{C}$ for $12 \mathrm{~h}$ to remove DNA and organic contaminants. Samples were stored in pre-baked aluminum bags after sampling at $-20^{\circ} \mathrm{C}$ for $1-30$ days and then at $-80^{\circ} \mathrm{C}$ after overnight, international transport cooled on dry ice. Due to the low vapor pressure of the molecular tracers analyzed, loss due to volatilization is considered unlikely (Zhang et al., 2010). A total of 36 samples were collected during the study, in addition to handling field blanks and operational field blanks. Handling blanks were acquired by placing a filter into the sampler and immediately removing it, without turning on the airflow control. Operational blanks were placed into the sampler and exposed to $10 \mathrm{~s}$ of airflow. 


\subsection{Slit sampler}

A direct-to-agar slit sampler (Microbiological Air Sampler STA-203, New Brunswick Scientific Co, Inc., Edison, NJ) was used to collect culturable airborne fungal spores. The sampler was placed $\sim 2 \mathrm{~m}$ above the ground on a wooden support surface with $5 \mathrm{~cm} \times 5 \mathrm{~cm}$ holes to allow airflow both up and down through the support structure. Sampled air was drawn over the $15 \mathrm{~cm}$ diameter sampling plate filled with growth media at a flow rate of $28 \mathrm{~L} \mathrm{~min}^{-1}$ for sampling periods of 20 to $40 \mathrm{~min}$. Growth media (malt extract medium) was mixed with antibacterial agents (40 units streptomycin, Sigma Aldrich; 20 units ampicillin, Fisher Scientific) to suppress bacterial colony growth. Plates were prepared several weeks in advance and stored in a refrigerator at ca. $4^{\circ} \mathrm{C}$ until used for sampling. Before each sampling period, all surfaces of the samplers were sterilized by wiping with isopropyl alcohol. Handling and operational blanks were collected to verify that no fungal colonies were being introduced by handling procedures. A total of 14 air samples were collected over 20 days and immediately moved to an incubator (Amerex Instruments, Incumax IC150R) set at $25^{\circ} \mathrm{C}$ for 3 days prior to counting fungal colonies formed. Each colony, present as a growing dot on the agar surface, was assumed to have originated as 1 colony-forming unit (CFU; i.e., fungal spore) deposited onto the agar by impaction during sampling. The atmospheric concentration of CFU per air volume was calculated using the sampler airflow. Further discussion of methods and initial results from the slit sampler were published by Huffman et al. (2013).

\subsection{Offline filter analyses}

\subsubsection{Carbohydrate analysis}

Approximately one-eighth of each frozen filter was cut for carbohydrate analysis using a sterile technique, meaning that scissors were cleaned and sterilized, and cutting was performed in a positive-pressure laminar flow hood. In order to precisely determine the fractional area of the filter to be analyzed, filters were imaged from a fixed distance above using a camera and compared to a whole, intact filter. Using ImageJ software (Rasband, 1997), the area of each filter slice showing particulate matter (PM) deposit was referenced to a whole filter, and thereby the amount of each filter utilized could be determined. The total PM mass was not measured and so this technique allowed for an estimation of the fraction of each sample used for the analysis, which corresponds to the fraction of PM mass deposited. The uncertainty on the filter area fraction is estimated at $2 \%$, determined as the percent of variation in the area of the filter edge (no PM deposit) as compared to the total filter area.

Water-soluble carbohydrates were extracted from glass fiber filter samples and analyzed following the procedure described by Rathnayake et al. (2016a). A total of 36 samples were analyzed along with field and lab blanks. All lab and field blanks fell below method detection limits. Extraction was performed by placing the filter slice into a centrifuge tube that had been pre-rinsed with Nanopure ${ }^{\mathrm{TM}}$ water (resistance $>18.2 \mathrm{M} \Omega \mathrm{cm}^{-1}$; Barnstead EasyPure II, 7401). A volume of $8.0 \mathrm{~mL}$ of Nanopure ${ }^{\mathrm{TM}}$ water was added to the filter in the centrifuge tube to extract water-soluble carbohydrates. Samples were then exposed to rotary shaking for $10 \mathrm{~min}$ at $125 \mathrm{rpm}$, sonication for $30 \mathrm{~min}$ at $60 \mathrm{~Hz}$ (Branson 5510, Danbury, CT, USA), and rotary shaking for another $10 \mathrm{~min}$. After shaking, the extracted solutions were filtered through a $0.45 \mu \mathrm{m}$ polypropylene syringe filter (GE Healthcare, UK) to remove insoluble particles, including disintegrated filter pieces. One $1.5 \mathrm{~mL}$ aliquot of each extracted solution was analyzed for carbohydrates within $24 \mathrm{~h}$ of extraction. A duplicate $1.5 \mathrm{~mL}$ aliquot was stored in a freezer and analyzed if necessary, due to lack of instrument response or invalid calibration check, within 7 days of extraction. Analysis of carbohydrates was done using a high-performance anion-exchange chromatography system with pulsed amperometric detection (HPAEC-PAD; Dionex ICS 5000, Thermo Fisher, Sunnyvale, CA, USA). Details of the instrument specifications and quality standards for carbohydrate determination are available in Rathnayake et al. (2016a). Calibration curves for mannitol, levoglucosan, glucose (Sigma-Aldrich), arabitol, and erythritol (Alfa Aesar) were generated with 7 points each, ranging in aqueous concentration from 0.005 to $5 \mathrm{ppm}$. The method detection limits for mannitol, levoglucosan, glucose, arabitol, and erythritol were determined to be $2.3,2.8,1.6,1.0$, and $0.6 \mathrm{ppb}$, respectively, by measuring the instrument response to filter extracts (Rathnayake et al., 2016a). One filter each was spiked with $10 \mathrm{ppb}$ of the five compounds, followed by one extraction per filter from which seven aliquots were each analyzed by the instrument. The variability ( $3 \mathrm{SD}$ ) of the measured response was taken as the method detection limit. All calibration curves were checked daily using a standard solution to ensure all concentration values were within $10 \%$ of the known value. Failure to maintain a valid curve resulted in recalibration of the instrument.

\subsubsection{DNA analysis}

Methods and initial results from DNA analysis from these high-volume filters were published by Huffman et al. (2013). Briefly, fungal diversity was determined by previously optimized methods for DNA extraction, amplification, and sequence analysis of the internal transcribed spacer regions of ribosomal genes from the high-volume filter samples (Fröhlich-Nowoisky et al., 2009, 2012). Upon sequence determination, fungal sequences were compared with known sequences using the Basic Local Alignment Search Tool (BLAST) at the National Center for Biotechnology (NCBI) and identified to the lowest taxonomic rank common to the top BLAST hits after chimeric sequences had been re- 
moved. When sequences displayed $>97 \%$ similarity, they were grouped into operational taxonomic units (OTUs).

\subsubsection{Endotoxin and glucan analysis}

Sample preparation for quantification of endotoxin and $(1 \rightarrow 3)$ - $\beta$-D-glucan included extraction of five punches $\left(0.5 \mathrm{~cm}^{2}\right.$ each) of the glass filters with $5.0 \mathrm{~mL}$ of pyrogenfree water (Associates of Cape Cod Inc., East Falmouth, MA, USA), utilizing an orbital shaker (300 rpm) at room temperature for $60 \mathrm{~min}$, followed by centrifuging for $15 \mathrm{~min}$ (1000 rpm). A $0.5 \mathrm{~mL}$ aliquot of supernatant was submitted to a kinetic chromogenic limulus amebocyte lysate (Chromo-LAL) endotoxin assay (Associates of Cape Cod Inc., East Falmouth, MA, USA), using a ELx808IU (BioTek Instrument Inc., Winooski, VT, USA) incubating absorbance microplate reader. For $(1 \rightarrow 3)-\beta$-D-glucan measurement, $0.5 \mathrm{~mL}$ of $3 \mathrm{~N} \mathrm{NaOH}$ was added to the remaining $4.5 \mathrm{~mL}$ of extract and the mixture was agitated for $60 \mathrm{~min}$. Subsequently, the solution was neutralized to $\mathrm{pH} 6-8$ by the addition of $0.75 \mathrm{~mL}$ of $2 \mathrm{~N} \mathrm{HCl}$. After centrifuging for $15 \mathrm{~min}$ $(1 \rightarrow 3)$ - $\beta$-D-glucan concentration was determined in the supernatant using the Glucatell ${ }^{\circledR}$ LAL kinetic assay (Associates of Cape Cod, Inc., East Falmouth, MA, USA). The minimum detection limits (MDLs) and reproducibility were 0.046 endotoxin units (EU) $\mathrm{m}^{-3} \pm 6.4 \%$ for endotoxin and $0.029 \mathrm{ng} \mathrm{m}^{-3} \pm 4.2 \%$ for $(1 \rightarrow 3)-\beta$-D-glucan, respectively. Laboratory and field blank samples were analyzed as well, with lab blank values being below detection limits, while field blank values were used to subtract background levels from sample data. More details about the bioassays can be found elsewhere (Chow et al., 2015a).

\subsection{Meteorology and wetness sensors}

Meteorological data were recorded by a variety of sensors located at the site. Precipitation was recorded by a laser optical disdrometer (PARticle SIze and VELocity sensor - "PARSIVEL"; OTT Hydromet GmbH, Kempton, Germany) and separately by a tipping-bucket rain gauge. The disdrometer provides precipitation occurrence, rate, and physical state (rain or hail) by measuring the magnitude and duration of disruption to a continuous $780 \mathrm{~nm}$ laser that was located in a tree clearing (Fig. 1), while the tipping-bucket rain gauge measures a set amount of precipitation before tipping and triggering an electrical pulse. A leaf wetness sensor (LWS; Decagon Devices, Inc., Pullman, WA, USA) provided a measurement of condensed moisture by measuring the voltage drop across a leaf surface to determine a proportional amount of water on or near the sensor. Additional details of these measurements can be found in Huffman et al. (2013) and Ortega et al. (2014).

\section{Results and discussion}

\subsection{Categorization and characteristic differences of Dry and Rainy periods}

Increases in PBAP concentration have been frequently associated with rainfall (e.g., Bigg et al., 2015; Faulwetter, 1917; Hirst and Stedman, 1963; Jones and Harrison, 2004; Madden, 1997). Fungal polyols have also been reported to increase after rain and have been used as indicators of increased fungal spore release (Liang et al., 2013; Lin and Li, 2000; Zhu et al., 2015). Recently, it was shown that the concentration of fluorescent aerosol particles (FAPs) measured during BEACHON-RoMBAS increased dramatically during and after periods of rain (Crawford et al., 2014; Huffman et al., 2013; Schumacher et al., 2013) and that these particles were associated with high concentrations of ice nucleating particles that could influence the formation and evolution of mixed-phase clouds (Huffman et al., 2013; Prenni et al., 2013; Tobo et al., 2013). It was observed that a mode of smaller fluorescent particles $(2-3 \mu \mathrm{m})$ appeared during rain episodes, and several hours after rain ceased a second mode of slightly larger fluorescent particles $(4-6 \mu \mathrm{m})$ emerged, persisting for up to $12 \mathrm{~h}$ (Huffman et al., 2013). The first mode was hypothesized to result from mechanical ejection of particles due to rain splash on soil and vegetated surfaces, and the second mode was suggested as actively emitted fungal spores (Huffman et al., 2013). While the UV-APS and WIBS each provide data at a high enough time resolution to see subtle changes in aerosol concentration, the temporal resolution of the chemical tracer analysis was limited to $4-48 \mathrm{~h}$ periods defined by the collection time of the high-volume sampler. To compare the measurement results across the sampling platforms, UV-LIF measurements were averaged to the lower time resolution of the filter sampler periods, and the periods were grouped into three broad categories: Rainy, Dry, and Other, as will be defined below.

Time periods were wetness-categorized in two steps: first at $15 \mathrm{~min}$ resolution and then averaged for each individual filter sample. During the first stage of categorization each 15 min period was categorized into one of four groups: rain, post-rain, dry, or other. To categorize each filter period, an algorithm was established utilizing UV-APS fluorescent particle fraction and accumulated rainfall. The ratio of the integrated number of fluorescent particles to total particles was used as a proxy for the increased emission of biological particles. Figure 2a presents a time series of the size-resolved fluorescent particle concentration, showing increases during rain periods in dark red. A relatively consistent diurnal cycle of increased FAP concentration in the $2-4 \mu \mathrm{m}$ range is apparent almost every afternoon, which corresponds to neardaily afternoon rainfall during approximately the first half of the measurement period. Disdrometer and tipping-bucket rainfall measurements were each normalized to unity and summed to produce a more robust, unitless measure of rain- 


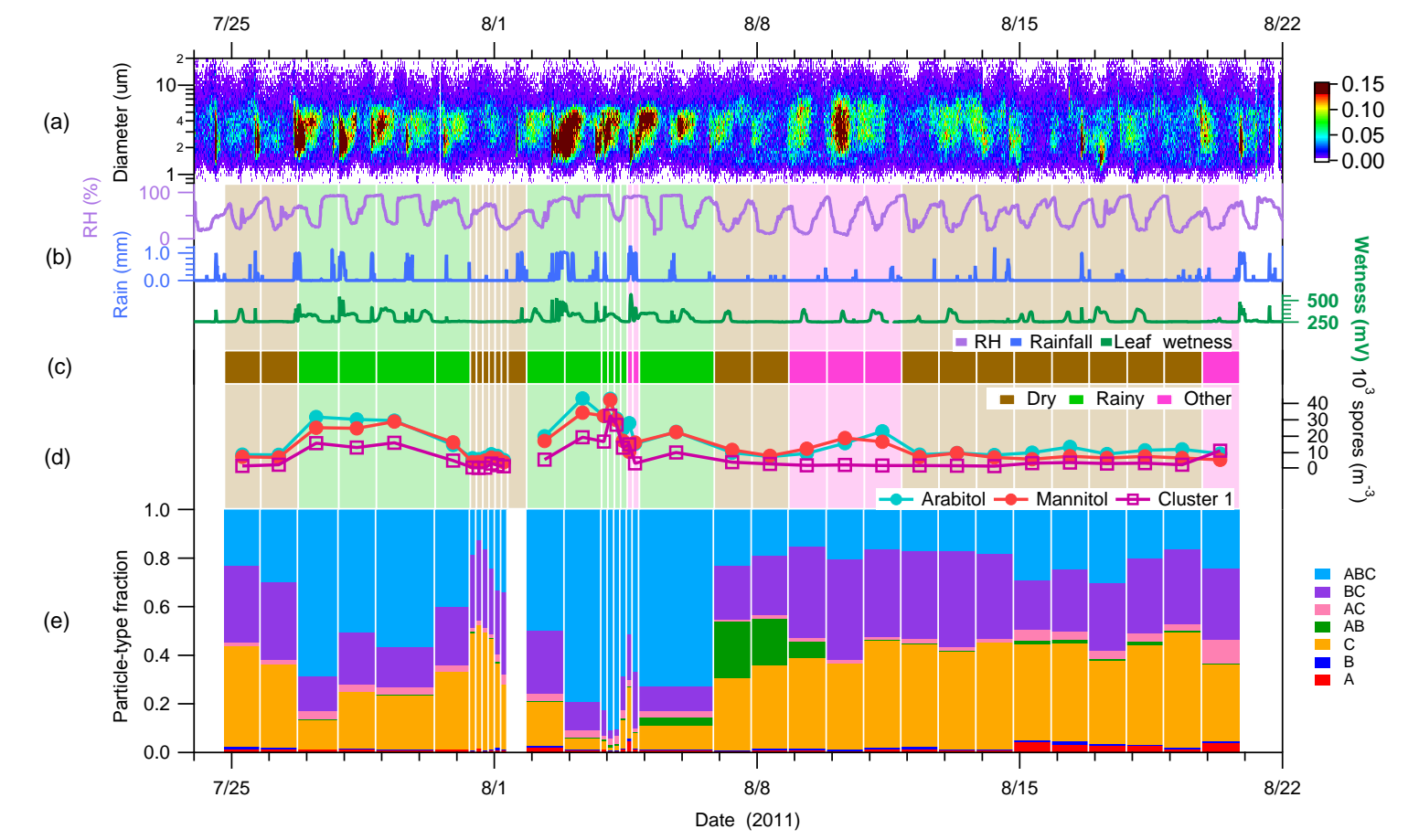

Figure 2. Time series of key species concentrations and meteorological data over entire campaign. (a) Fluorescent particle number size distribution measured with UV-APS instrument. Color scale indicates fluorescent particle number concentration $\left(\mathrm{L}^{-1}\right)$. (b) Meteorological data: relative humidity $(\mathrm{RH})$, disdrometer rainfall (millimeters per $15 \mathrm{~min})$, leaf wetness $(\mathrm{mV})$. (c) Wetness category indicated as colored bars: green, Rainy; brown, Dry; pink, Other. Bar width corresponds to filter sampling periods. Lightened colored bars extend vertically to highlight categorization. (d) Colored traces show fungal spore concentrations estimated from molecular tracers (circles) and WIBS Cl1 data (squares). (e) Stacked bars show relative fraction of fluorescent particle type corresponding to each WIBS category.

fall rate because it was observed that often only one of the two systems would record a given light rain event. If a point was described by total rainfall accumulation greater than 0.201 it was flagged as rain. A point was flagged as post-rain if it immediately followed a rain period and also exhibited a fluorescent particle fraction greater than 0.08 . The purpose of this category was to reflect the observation that sustained elevated concentrations of FAPs persisted for many hours even after the rain rate, $\mathrm{RH}$, and leaf wetness returned to pre-rain values. The only measurement that adequately reflected this scenario was of the fluorescent particles measured by UVAPS and WIBS instruments. The post-rain flag was continued until the fluorescent particle fraction fell below 0.08 or if it started to rain again (with calculated rain values greater than 0.201). Points were flagged as dry periods if they exhibited rainfall accumulation and fluorescent particle fraction below the thresholds stated above. Several periods were not easily categorized by this system and were considered in a fourth category as other. This occurred when fluorescent particle fraction above the threshold value was observed with no discernable rainfall.

Once wetness categories were assigned by the algorithm at 15 min resolution, each high-volume filter sample was categorized by a similar nomenclature, but using only three cat- egories. These were defined as Dry, Rainy (combination of rain and post-rain categories), or Other based on the relative time fraction in each of the four original $15 \mathrm{~min}$ categories. For each sample, if a given category represented more than $50 \%$ of the 15 min periods, the sample was assigned to that category. Despite the effort to categorize samples systematically, several sample periods (5 of 35) appeared mis-categorized by looking at FAP concentration, rainfall, RH, and leaf wetness in more detail. In some circumstances, this was because light rainfall produced observable increases in FAPs, but without exceeding the rainfall threshold. Or in other circumstances a period of rainfall occurred at the very end or just before the beginning of a sample, and so the many-hour period was heavily influenced by aerosol triggered by a period of rain just outside of the sample time window. As a result, several samples were manually re-categorized as described here. Samples 20 and 21 (Table $\mathrm{S} 1$ ) were $4 \mathrm{~h}$ samples that displayed high relative humidity and rainfall; thus, samples were originally characterized as Rainy. This period was described by an extremely heavy rain downpour ( $7.5 \mathrm{~mm}$ in $15 \mathrm{~min}$ ); however, that seemingly placed the samples in a different regime of rain-aerosol dynamics than the other Rainy samples and so these two samples were moved to the Other category. Sample 23, originally 
Rainy, presented a FAP fraction marginally above the 0.08 threshold, but visually displayed a trend dissimilar to other post-rain periods and so was re-categorized as Dry. Sample 28 showed no obvious rainfall, but the measurement team observed persistent fog in three consecutive mornings (samples $25,27,28)$, and the concentration of fluorescent particles $(2-6 \mu \mathrm{m})$ suggested a source of particles not influenced by rain, and so this Rainy sample was re-categorized as Other. Sample 38 displayed a fluorescent number ratio just below the threshold value, and was first categorized as Dry; however, the measurement team observed post-rain periods at the beginning and end of the sample, and the sample was re-categorized as Other. For all samples other than these five, the categorization was determined using the majority $(>0.50)$ of the 15 min periods. In no cases other than the five that were re-categorized was the highest category fraction less than 0.50 of the sample time. Note that we have chosen to capitalize Rainy, Dry, and Other to highlight that we have rigorously defined the period using the characterization scheme described above and to separate the nomenclature from the general, colloquial usage of the terms. Wetness category assignment for each high-volume filter sample period is shown in Fig. 2 as a background color (brown for Dry samples, green for Rainy samples, and pink for Other samples) and Table S1.

To validate the qualitative differences between wetness categories described in the last section, we present observations about each of these groupings. First, we organized the WIBS data according to the particle categories introduced by Perring et al. (2015). By this method, every fluorescent particle detected by the WIBS can be defined uniquely into one of seven categories (i.e., A, AB, ABC). By plotting the relative fraction of fluorescent particles described by each particle type, temporal differences between measurement periods can be observed, as shown in Fig. 2e. To a first approximation, this analysis style allows for coarse discrimination of particle types. For example, a given population of particles would ideally exhibit a consistent fraction of particles present in the different particle categories as a function of time. By this reasoning, sample periods categorized as Dry (most of the latter half of the study; brown bars in Fig. 2) would be expected to have a self-consistent particle-type trend, whereas sample periods categorized as Rainy (most of the first half of the study; green bars in Fig. 2) would have a self-consistent particle-type trend, but different from the Dry samples. This is broadly true. During Rainy periods, as seen in Fig. 3a, there is a relatively high fraction (>65\%) of ABC type particles (light blue) and a relatively low fraction $(<15 \%)$ in $\mathrm{BC}$ (purple) and $\mathrm{C}$ (yellow) type particles, suggesting heavy influence from the FL1 channel. In contrast, during Dry periods the fraction of $\mathrm{ABC}$ particles (light blue) is reduced $(<25 \%)$, whereas BC (purple) and C (yellow) type particles increase in relative fraction ( $>30$ and $>40 \%$, respectively), which suggested a diminished influence of FL1 channel.
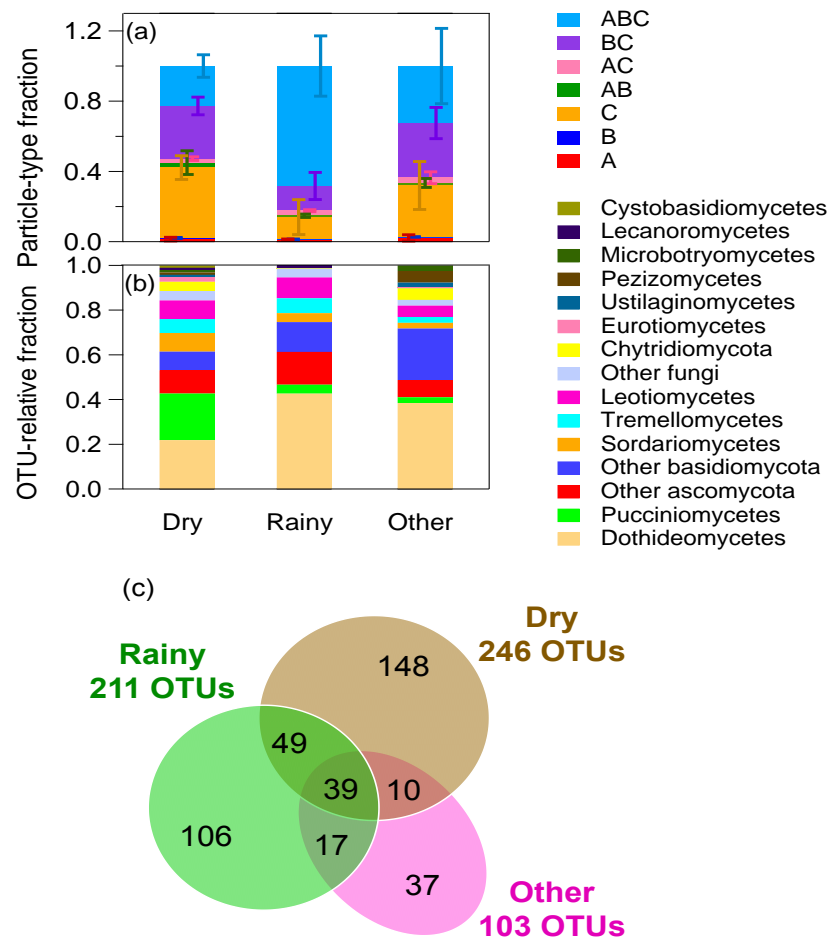

Figure 3. Characteristic differences between wetness periods (Dry, Rainy, Other). (a) Relative fraction of fluorescent particle number corresponding to each WIBS category. Bars show relative standard deviation of category fraction in each wetness group (Dry, 19 samples; Rainy, 11 samples; Other, 6 samples). (b, c) Distribution of fungal OTU (operational taxonomic unit) values. (b) Fungal community composition at phylum and class level with Agaricomycetes (dominant class with consistently $\sim 60 \%$ of diversity) removed. Relative proportion of OTUs assigned to different fungal classes and phyla for each sample category shown. (c) Venn diagram showing the number of unique (wetness category-specific) and shared OTUs (represented by numbers in overlapping areas) among the sample categories (Dry, 11 samples; Rainy, 7 samples; Other, 3 samples). OTUs classified as cluster of sequences with $\geq 97 \%$ similarity. Taxonomic assignments were performed using BLAST against NCBI database. In total, 3902 sequences, representing 406 fungal OTUs from 3 phyla and 12 classes were detected. Despite differences in community structure across the sample categories, phylogenetic representation appears largely similar.

It is important to note a few caveats here. First, the ability of the WIBS to discriminate distinctly between PBAP types is relatively poor and it is still unclear exactly how different particle types would appear by this analysis method. Particles of different kinds and from different sources are likely convolved into a single WIBS particle type, which could either soften or enhance the relationships with rain discussed here. Second, the assignment of particle types is heavily size dependent and sensitive to subtle instrument parameters, and so it is unclear how different instruments would present similar particle types. For example, Hernandez et al. (2016) used two WIBS instruments and found differences in relative frac- 

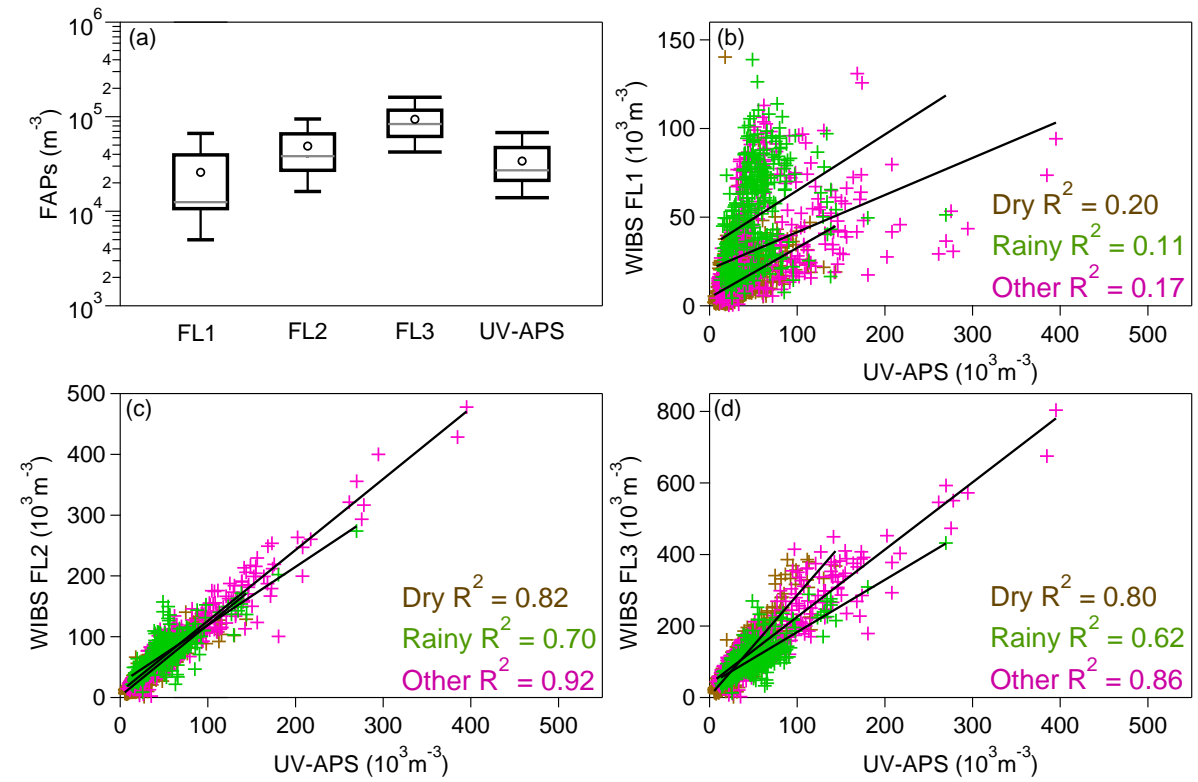

Figure 4. Number concentration of fluorescent particles as a function of instrument channel, averaged over entire measurement period. (a) Box-and-whisker plot of fluorescent particle number concentration for WIBS FL1, FL2, FL3, and UVAPS. Circle markers shows mean values, internal gray horizontal line shows median, top and bottom of box show inner quartile, and whiskers show 5th and 95th percentiles. (b) WIBS FL1 vs. UV-APS, (c) WIBS FL2 vs. UV-APS, and (d) WIBS FL3 vs. UV-APS. Crosses represent 5 min average points. Linear fits assigned for data in each wetness category.

tion of particle categories for samples aerosolized in the lab. They reported fungal spores to be predominately $\mathrm{A}, \mathrm{AB}$, and ABC type particles, whereas Rainy sample periods, suggested to have a heavy fungal spore influence by Huffman et al. (2013), show predominantly C, BC, and ABC type particle fractions. These discrepancies may be due to the comparison of ambient particles to laboratory-grown cultures. The highly controlled environment of a laboratory may not always accurately represent the humidity conditions in which fungal spore release occurs in this forest setting (Saari et al., 2015). This could impact the fluorescence properties of fungal spore particles that have different amounts of adsorbed or associated water (Hill et al., 2009, 2013, 2015). More likely, however, is that the WIBS-3 used here exhibits differences in fluorescence sensitivity from the WIBS-4A used by Hernandez et al. (2016). Even a slight increase in sensitivity in the FL3 channel with respect to the FL1 or FL2 channels could explain the shift here towards particles with C-type fluorescence. One piece of evidence for this is the quantitative comparison of particle measurements presented by the UV-APS and WIBS-3 instruments co-deployed here (Fig. 4). The number concentration of particles exhibiting fluorescence above the FL2 baseline of the WIBS-3 is approximately consistent with the number of fluorescent particles measured by the UV-APS, and significantly below the concentration of FL3 particles. The UV-APS number concentration shows the highest correlation with the WIBS-3 FL2 channel: during Rainy periods, $R^{2}=0.70$; Dry, $R^{2}=0.82$; and Other, $R^{2}=0.92$. These observations are in stark contrast to the trends reported by Healy et al. (2014) that the UV-APS fluorescent particle concentration correlated most strongly with the WIBS-4 FL3 and that the number concentration of FL3 was the lowest out of all three channels. Given that the FL3 channel of the WIBS and the UV-APS cover similar excitation and emission wavelengths, it is expected that these two channels should correlate well. Based on these data, we suggest that the WIBS-3 utilized here may present a very different particle-type breakdown than if a WIBS-4 had been used. So, while caution is recommended when comparing the relative breakdown of WIBS particle categories shown here (Fig. 3) with other studies, the data are internally self-consistent, and comparing qualitative differences between, e.g., Rainy and Dry periods, is expected to be robust. The main point to be highlighted here is that there is indeed a qualitative difference in particles present in the three wetness categories, as averaged and shown in Fig. 3a, which generally supports the effort to segregate these samples.

Further evidence that there is a qualitative difference in the three wetness categories is shown using molecular genetic analysis (Fig. 3b, c). The analysis of fungal DNA sequences from 21 of the high-volume samples found 406 OTUs belonging to different fungal classes and phyla. When organized by wetness type it was observed that 106 of these occurred only on Rainy samples, 148 of these occurred on Dry samples, and 37 on Other samples, with some fraction occurring in overlaps of each (Fig. 3c). This shows that the 

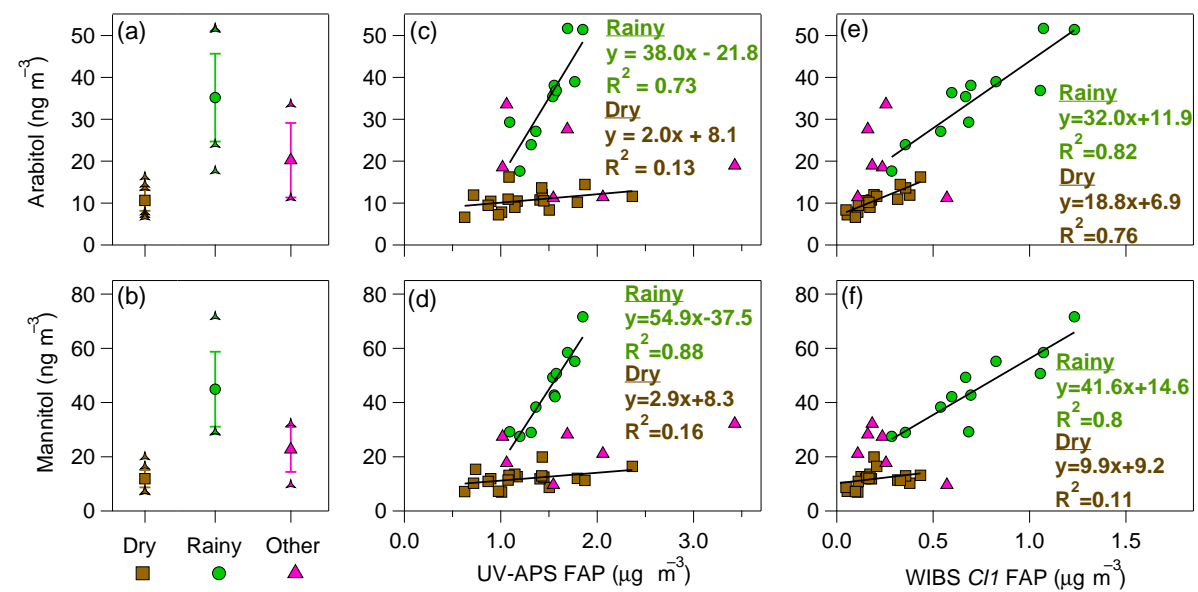

Figure 5. Mass concentrations of molecular tracers and fluorescent particles (calculated assuming unit density particle mass and spherical particles): arabitol - top row and mannitol - bottom row. Average mass concentration of arabitol (a) and mannitol (b) in each wetness category. Central marker shows mean value of individual filter concentration values, bars represent standard deviation (SD) range of filter values, and individual points show outliers beyond mean \pm SD. Correlation of arabitol (c) and mannitol (d) with fluorescent particle mass from UV-APS. Correlation of arabitol (e) and mannitol (f) with fluorescent particle mass from WIBS cluster 1. $R^{2}$ values shown for each fit in (c-f). Linear fit parameters are shown in Table S2.

number of OTUs observed uniquely in either the Rainy or Dry periods is greater than the number of OTUs present in both wetness types, suggesting that the fungal communities in each grouping are relatively distinct. Further, Fig. 3b shows a breakdown of fungal taxonomic groupings for each wetness group. This analysis shows that there is a qualitative difference in taxonomic breakdown between periods of Rainy and Dry. Specifically, during Dry periods there is an increased fraction of Pucciniomycetes (green bar, Fig. 3c), Chytridiomycota (yellow), Sordariomycetes (orange), and Eurotiomycetes (pink) when compared to the Rainy periods.

\subsection{Atmospheric mass concentration of arabitol, mannitol, and fungal spores}

To estimate fungal spore emission to the atmosphere, the concentration of arabitol and mannitol (Fig. 5a, b, Table 1) in each aerosol sample was averaged for all samples in each of the three wetness categories. The average concentration of arabitol collected on Rainy TSP samples $\left(35.2 \pm 10.5 \mathrm{ng} \mathrm{m}^{-3}\right)$ increased by a factor of 3.3 with respect to Dry samples, and the average mannitol concentration on Rainy samples was higher by a factor of 3.7 $\left(44.9 \pm 13.8 \mathrm{ng} \mathrm{m}^{-3}\right)$. Figure $5 \mathrm{a}, \mathrm{b}$ show the concentration variability for each wetness category, observed as the standard deviation from the distribution of individual samples. For each polyol, there is no overlap in the ranges shown, including the outliers of the Rainy and Dry category, suggesting a definitive and conceptually distinct separation between dry periods and those influenced by rain. The concentrations observed during Other periods is between those of the Dry and Rainy averages, as expected, given the difficulty in confidently assigning these uniquely to one of these categories. The observations here are roughly consistent with previous reports of polyol concentration, despite differences in local fungal communities and concentrations. For example, Rathnayake et al. (2016a) observed $30.2 \mathrm{ng} \mathrm{m}^{-3}$ arabitol and $41.3 \mathrm{ng} \mathrm{m}^{-3}$ mannitol in $\mathrm{PM}_{10}$ samples collected in rural Iowa, USA. In addition, Zhang et al. (2015) reported arabitol and mannitol concentrations in $\mathrm{PM}_{10}$ samples of 44.0 and $71.0 \mathrm{ng} \mathrm{m}^{-3}$, respectively, from a study in the mountains on Hainan Island off the coast of southern China. More recently, Yue et al. (2016) studied a rain event in Beijing and observed increased polyol concentrations at the onset of the rain. The observed mannitol concentration $\left(45 \mathrm{ng} \mathrm{m}^{-3}\right)$ was approximately consistent with observations reported here and with previous reports, while the arabitol concentration values observed were approximately an order of magnitude lower $\left(0.3 \mathrm{ng} \mathrm{m}^{-3}\right)$.

The square of the correlation coefficient $\left(R^{2}\right)$ here between concentration values of arabitol and mannitol during Rainy samples is very high (0.839; Table 2$)$ suggesting that arabitol and mannitol originated primarily from the same source, likely active-discharge fungal spores. The correlation is similar to the $0.87 R^{2}$ reported by Bauer et al. (2008a) and the $0.93 R^{2}$ reported by Graham et al. (2003). In contrast, the same correlation seen between mannitol and arabitol concentrations for Dry samples is relatively low (0.312). This is consistent with reports that arabitol can be used more specifically as a spore tracer, but that mannitol has additional atmospheric sources besides fungal spores. The same correlation was also performed between arabitol or mannitol and other molecular tracers (endotoxins and ( $1 \rightarrow 3)-\beta$-D-glucan), but all $R^{2}$ value were less than 0.43 , suggesting that the endo- 
Table 1. Campaign-average concentrations of molecular tracers (top) and their respective mass contributions (bottom). Values are mean \pm standard deviation; $n$ shows number of samples used for averaging. Total particulate matter mass calculated from UV-APS number concentration $\left(\mathrm{m}^{-3}\right)$, converted to mass over aerodynamic particle diameter range $0.5-15 \mu \mathrm{m}$ using $1.5 \mathrm{~g} \mathrm{~cm}^{-3} \mathrm{density}$.

\begin{tabular}{|c|c|c|c|c|c|c|c|}
\hline & \multicolumn{7}{|c|}{ Mass concentration } \\
\hline & $\begin{array}{l}\text { Arabitol } \\
\left(\mathrm{ng} \mathrm{m}^{-3}\right)\end{array}$ & $\begin{array}{l}\text { Mannitol } \\
\left(\mathrm{ng} \mathrm{m}^{-3}\right)\end{array}$ & $\begin{array}{l}\text { Erythritol } \\
\left(\text { ng m }^{-3}\right)\end{array}$ & $\begin{array}{l}\text { Levoglucosan } \\
\left(\mathrm{ng} \mathrm{m}^{-3}\right)\end{array}$ & $\begin{array}{l}\text { Glucose } \\
\left(\mathrm{ng} \mathrm{m}^{-3}\right)\end{array}$ & $\begin{array}{l}\text { Endotoxins } \\
\left(\mathrm{EU} \mathrm{m}^{-3}\right)\end{array}$ & $\begin{array}{l}(1 \rightarrow 3)-\beta \text {-D-glucan } \\
\left(\mathrm{pg} \mathrm{m}^{-3}\right)\end{array}$ \\
\hline Dry & $\begin{array}{l}10.6 \pm 2.5 \\
n=18\end{array}$ & $\begin{array}{l}11.9 \pm 3.2 \\
n=18\end{array}$ & $\begin{array}{l}0.840 \pm 0.610 \\
n=16\end{array}$ & $\begin{array}{l}14.2 \pm 10.7 \\
n=15\end{array}$ & $\begin{array}{l}38.7 \pm 21.3 \\
n=18\end{array}$ & $\begin{array}{l}0.192 \pm 0.0970 \\
n=18\end{array}$ & $\begin{array}{l}8.85 \pm 7.68 \\
n=18\end{array}$ \\
\hline Rainy & $\begin{array}{l}35.2 \pm 10.5 \\
n=11\end{array}$ & $\begin{array}{l}44.9 \pm 13.8 \\
n=11\end{array}$ & $\begin{array}{l}1.12 \pm 0.38 \\
n=3\end{array}$ & $\begin{array}{l}12.4 \pm 19.1 \\
n=8\end{array}$ & $\begin{array}{l}73.2 \pm 50.5 \\
n=11\end{array}$ & $\begin{array}{l}1.43 \pm 1.22 \\
n=10\end{array}$ & $\begin{array}{l}10.6 \pm 8.2 \\
n=11\end{array}$ \\
\hline Other & $\begin{array}{l}20.2 \pm 8.9 \\
n=6\end{array}$ & $\begin{array}{l}22.7 \pm 8.3 \\
n=6\end{array}$ & $\begin{array}{l}0.664 \pm 0.515 \\
n=6\end{array}$ & $\begin{array}{l}9.21 \pm 1.66 \\
n=5\end{array}$ & $\begin{array}{l}56.5 \pm 39.2 \\
n=6\end{array}$ & $\begin{array}{l}0.311 \pm 0.159 \\
n=6\end{array}$ & $\begin{array}{l}6.08 \pm 6.08 \\
n=6\end{array}$ \\
\hline & \multicolumn{7}{|c|}{ Mass contribution $(\%)$} \\
\hline Dry & $\begin{array}{l}0.18 \% \pm 0.05 \\
n=18\end{array}$ & $\begin{array}{l}0.20 \% \pm 0.073 \\
n=18\end{array}$ & $\begin{array}{l}0.014 \% \pm 0.011 \\
n=16\end{array}$ & $\begin{array}{l}0.21 \% \pm 0.17 \\
n=15\end{array}$ & $\begin{array}{l}0.67 \% \pm 0.49 \\
n=18\end{array}$ & & $\begin{array}{l}0.16 \% \pm 0.16 \\
n=18\end{array}$ \\
\hline Rainy & $\begin{array}{l}0.83 \% \pm 0.32 \\
n=11\end{array}$ & $\begin{array}{l}1.07 \% \pm 0.44 \\
n=11\end{array}$ & $\begin{array}{l}0.032 \% \pm 0.009 \\
n=3\end{array}$ & $\begin{array}{l}0.27 \% \pm 0.41 \\
n=8\end{array}$ & $\begin{array}{l}1.60 \% \pm 1.09 \\
n=11\end{array}$ & & $\begin{array}{l}0.25 \% \pm 0.21 \\
n=11\end{array}$ \\
\hline Other & $\begin{array}{l}0.25 \% \pm 0.28 \\
n=6\end{array}$ & $\begin{array}{l}0.37 \% \pm 0.29 \\
n=6\end{array}$ & $\begin{array}{l}0.013 \% \pm 0.015 \\
n=6\end{array}$ & $\begin{array}{l}0.15 \% \pm 0.11 \\
n=5\end{array}$ & $\begin{array}{l}0.83 \% \pm 0.64 \\
n=6\end{array}$ & & $\begin{array}{l}0.12 \% \pm 0.19 \\
n=6\end{array}$ \\
\hline
\end{tabular}

Table 2. Square of correlation coefficients $\left(R^{2}\right)$ comparing total mass concentration of molecular tracers to each other. EU: endotoxin units. Boxes colored by coefficient value (bold $>0.7 ; 0.7>$ italic $>0.4$ ).

\begin{tabular}{|c|c|c|c|c|c|c|c|}
\hline & & \multicolumn{2}{|c|}{ Arabitol } & \multicolumn{2}{|c|}{ Mannitol } & \multicolumn{2}{|c|}{$(1 \rightarrow 3)$ - $\beta$-D-glucan } \\
\hline & & Rainy & Dry & Rainy & Dry & Rainy & Dry \\
\hline \multirow{2}{*}{ Mannitol } & Rainy & 0.839 & & & & & \\
\hline & Dry & & 0.312 & & & & \\
\hline \multirow{2}{*}{$(1 \rightarrow 3)-\beta$-D-glucan } & Rainy & 0.000 & & 0.003 & & & \\
\hline & Dry & & 0.000 & & 0.327 & & \\
\hline \multirow{2}{*}{ Endotoxins } & Rainy & 0.116 & & 0.126 & & 0.427 & \\
\hline & Dry & & 0.012 & & 0.113 & & 0.103 \\
\hline
\end{tabular}

toxins and glucans analyzed were not emitted uniquely from the same sources as arabitol and mannitol.

Results from the two UV-LIF instruments were averaged over high-volume sample periods, and a correlation analysis was performed between tracer mass and fluorescent particle mass showing positive correlations in all cases. The FAP mass from the UV-APS shows high correlation with the fungal polyols during Rainy periods, with $R^{2}$ of 0.732 and 0.877 for arabitol and mannitol, respectively (Table 3; Fig. 5c, d). The same tracers correlate poorly with the UV-APS during Dry conditions. This is expected, because Ascomycota and Basidiomycota spores emitted by wet-discharge methods are the only fungal spores reported to be associated with arabitol and mannitol (Elbert et al., 2007; Feofilova, 2001; Lewis and Smith, 1967). This high correlation suggests that the UVAPS does a good job of detecting these wet-discharge spores, and corroborates previous statements that particles detected in ambient air by the UV-APS are often predominately fungal spores (Healy et al., 2014; Huffman et al., 2012, 2013).
In contrast, the low slope value and the poor correlation during Dry periods suggest that the UV-APS is also sensitive to other kinds of particles, as designed. The small positive $x$ offset (FAP mass; Table S2, Fig. 5c, d) during Rainy periods is likely due to particles that are too weakly fluorescent to be detected and counted by the UV-APS, which is consistent with observations made in Brazil (Huffman et al., 2012).

Particle mass from WIBS Cl1, assigned to fungal spores (Crawford et al., 2015), also correlate strongly with the same two molecular tracers. Both Rainy periods $\left(R^{2} 0.824\right)$ and Dry periods $\left(R^{2} 0.764\right)$ correlate well with arabitol (Fig. 5e), while mannitol (Fig. 5f) only shows a strong correlation during the Rainy periods $\left(R^{2} 0.799\right)$. Mannitol is a common polyol in higher plants while arabitol is only found in fungal spores and lichen (Lewis and Smith, 1967). So the strong correlation of each polyol with UV-LIF mass during Rainy periods when actively discharged spores are expected to dominate and the similarly strong correlations associated with arabitol suggest that the $\mathrm{Cl1}$ cluster does a reasonably good job 
Table 3. Square of correlation coefficients $\left(R^{2}\right)$ comparing fluorescent particle measurements from UV-LIF instruments to measurements from molecular tracers and direct-to-agar sampler. Columns marking tracer mass indicate correlations between time-averaged UV-LIF and tracer mass concentrations (left side). Columns marking fungal spore count indicate correlations between fungal spore number concentrations estimated from time-averaged UV-LIF and tracer or culture measurements (right side). FL1, FL2, FL3 represent individual channels from the WIBS. FL represents particles exhibiting fluorescence in any channel. $\mathrm{Cl1}, \mathrm{Cl} 2, \mathrm{Cl} 3, \mathrm{Cl} 4$ are clusters that estimate particle concentrations as a mixture of various channels (Crawford et al., 2015). $\mathrm{Cl}_{\text {Bact }}$ is a sum of the "bacteria" clusters Cl2-4. Boxes colored by coefficient value (bold >0.7; $0.7>$ italic $>0.4$ ).

\begin{tabular}{|c|c|c|c|c|c|c|c|c|c|c|c|c|c|c|c|c|}
\hline & & & \multicolumn{8}{|c|}{ Correlation based on tracer mass } & \multicolumn{6}{|c|}{ Correlation based on spore counts } \\
\hline & & & \multicolumn{2}{|c|}{ Arabitol } & \multicolumn{2}{|c|}{ Mannitol } & \multicolumn{2}{|c|}{$(1 \rightarrow 3)-\beta$-D-glucan } & \multicolumn{2}{|c|}{ Endotoxins } & \multicolumn{2}{|c|}{ Arabitol } & \multicolumn{2}{|c|}{ Mannitol } & \multicolumn{2}{|c|}{$\mathrm{CFU}$} \\
\hline & & & Rainy & Dry & Rainy & Dry & Rainy & Dry & Rainy & Dry & Rainy & Dry & Rainy & Dry & Rainy & Dry \\
\hline \multirow{10}{*}{ 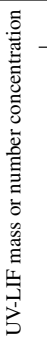 } & UVAPS & & 0.732 & 0.127 & 0.877 & 0.160 & 0.006 & 0.012 & 0.153 & 0.067 & 0.483 & 0.278 & 0.504 & 0.571 & 0.469 & 0.491 \\
\hline & & FL & 0.554 & 0.250 & 0.810 & 0.255 & 0.128 & 0.010 & 0.068 & 0.066 & 0.159 & 0.200 & 0.088 & 0.314 & 0.330 & 0.737 \\
\hline & & FL1 & 0.602 & 0.445 & 0.819 & 0.412 & 0.042 & 0.001 & 0.090 & 0.012 & 0.667 & 0.339 & 0.863 & 0.621 & 0.470 & 0.546 \\
\hline & & FL2 & 0.617 & 0.248 & 0.843 & 0.342 & 0.092 & 0.001 & 0.039 & 0.094 & 0.485 & 0.302 & 0.442 & 0.340 & 0.560 & 0.543 \\
\hline & & FL3 & 0.561 & 0.222 & 0.818 & 0.251 & 0.124 & 0.008 & 0.071 & 0.065 & 0.178 & 0.181 & 0.104 & 0.306 & 0.367 & 0.736 \\
\hline & WIBS & $\mathrm{Cl} 1$ & 0.824 & 0.764 & 0.799 & 0.109 & 0.000 & 0.134 & 0.229 & 0.011 & 0.679 & 0.543 & 0.775 & 0.423 & 0.128 & 0.690 \\
\hline & & $\mathrm{Cl} 2$ & 0.005 & 0.002 & 0.004 & 0.006 & 0.002 & 0.047 & 0.006 & 0.017 & 0.052 & 0.056 & 0.001 & 0.075 & 0.081 & 0.930 \\
\hline & & $\mathrm{Cl} 3$ & 0.267 & 0.164 & 0.261 & 0.198 & 0.003 & 0.011 & 0.016 & 0.066 & 0.052 & 0.116 & 0.087 & 0.439 & 0.262 & 0.383 \\
\hline & & $\mathrm{Cl} 4$ & 0.048 & 0.046 & 0.172 & 0.118 & 0.115 & 0.011 & 0.179 & 0.145 & 0.062 & 0.089 & 0.001 & 0.065 & 0.120 & 0.000 \\
\hline & & $\mathrm{Cl}_{\text {Bact }}$ & & & & & & & 0.041 & 0.081 & & & & & & \\
\hline
\end{tabular}

of selecting fungal spore particles. The poor correlation between mannitol and Cl1 during dry periods illustrates that the background mannitol concentration is likely not due to fungal spores alone, but has contributions from other higher plants that contain mannitol. Particle concentrations detected by individual WIBS channels and in the other clusters were also compared with polyol concentrations, but each correlation is relatively poor compared to that with respect to Cl1. As seen in Table 3 and Figs. S2-S3, correlations in FL1, 2, and 3 with arabitol are poor $(<0.4)$ in the Dry category and good $\left(0.4<R^{2}<0.7\right)$ in the Rainy category. For mannitol, all the UV-LIF instruments show high correlation $(>0.7)$ in all cases. This is likely due to mannitol being a non-specific tracer and suggests that the majority of UV-LIF particles observed during all periods was dominated by PBAPs.

\subsection{Estimated number concentration of fungal spore aerosol}

Bauer et al. (2008a) reported measurements of fungal spore number concentration in Vienna, Austria, using epifluorescence microscopy, and also measured fungal tracer mass collected onto filters in order to estimate the mass of arabitol (1.2 to $2.4 \mathrm{pg}_{\text {spore }}{ }^{-1}$ ) and mannitol (0.8 to $1.8 \mathrm{pg}_{\text {spore }}{ }^{-1}$ ) associated with each emitted spore. Bauer et al. (2008a) and Yttri et al. (2011b) reported ratios of mannitol to arabitol of ca. 1.5 ( \pm standard deviation of $26 \%$ ) and $1.4 \pm 0.3$, respectively. Our measurements show slightly lower ratios of mannitol to arabitol, but that the ratio is dependent on wetness category: Rainy, $1.29 \pm 0.17$; Dry, $1.12 \pm 0.23$; and Other, $1.24 \pm 0.54$. The mannitol to arabitol ratio would be expected to vary as a function of fungal population present in the aerosol, whether between different wetness periods at a given location or between different physical localities.

Using the approximate mid-point of the Bauer et al. (2008a) reported ranges, $1.7 \mathrm{pg}$ mannitol per spore and $1.2 \mathrm{pg}$ arabitol per spore, atmospheric number concentrations of spores collected onto the high-volume filters were calculated from the polyol mass concentrations measured here. Based on these values, and assuming all polyol mass originated with spore release, the mass concentration averages (Fig. 5) were converted to fungal spore number concentrations (Fig. 6). The trends of spore concentration averages are the same as with the polyol mass, because the numbers were each multiplied by the same scalar value. After doing so, the analysis reveals an estimated spore concentration during Dry periods of $0.89 \times 10^{4}( \pm 0.21)$ spores $\mathrm{m}^{-3}$ using the arabitol concentration and $0.70 \times 10^{4}( \pm 0.19)$ spores $\mathrm{m}^{-3}$ using the mannitol concentration (Table 4). The estimated concentration of spores increased approximately 3 -fold during Rainy periods to $2.9 \times 10^{4}( \pm 0.8)$ spores $\mathrm{m}^{-3}$ (arabitol estimate) and $2.6 \times 10^{4}( \pm 0.8)$ spores $\mathrm{m}^{-3}$ (mannitol estimate) (Fig. 6a, b). These estimates match reasonably well with estimates reported by Spracklen and Heald (2014), who modeled the concentration of airborne fungal spores across the globe as an average of $2.5 \times 10^{4}$ spores $^{-3}$, with ca. $0.5 \times 10^{4}$ spores $\mathrm{m}^{-3}$ over Colorado.

The UV-LIF instruments discussed here are numbercounting techniques and in this instance have been applied as spore counters. As a first approximation, each particle detected by the UV-APS was assumed to be a fungal spore with the same properties used in the assumptions by Bauer et al. (2008a). Figure 6d, e, g, h show correlations of fungal spore number concentration estimated from polyol mass on the $y$ axes and from UV-LIF measurements on the $x$ axes. 

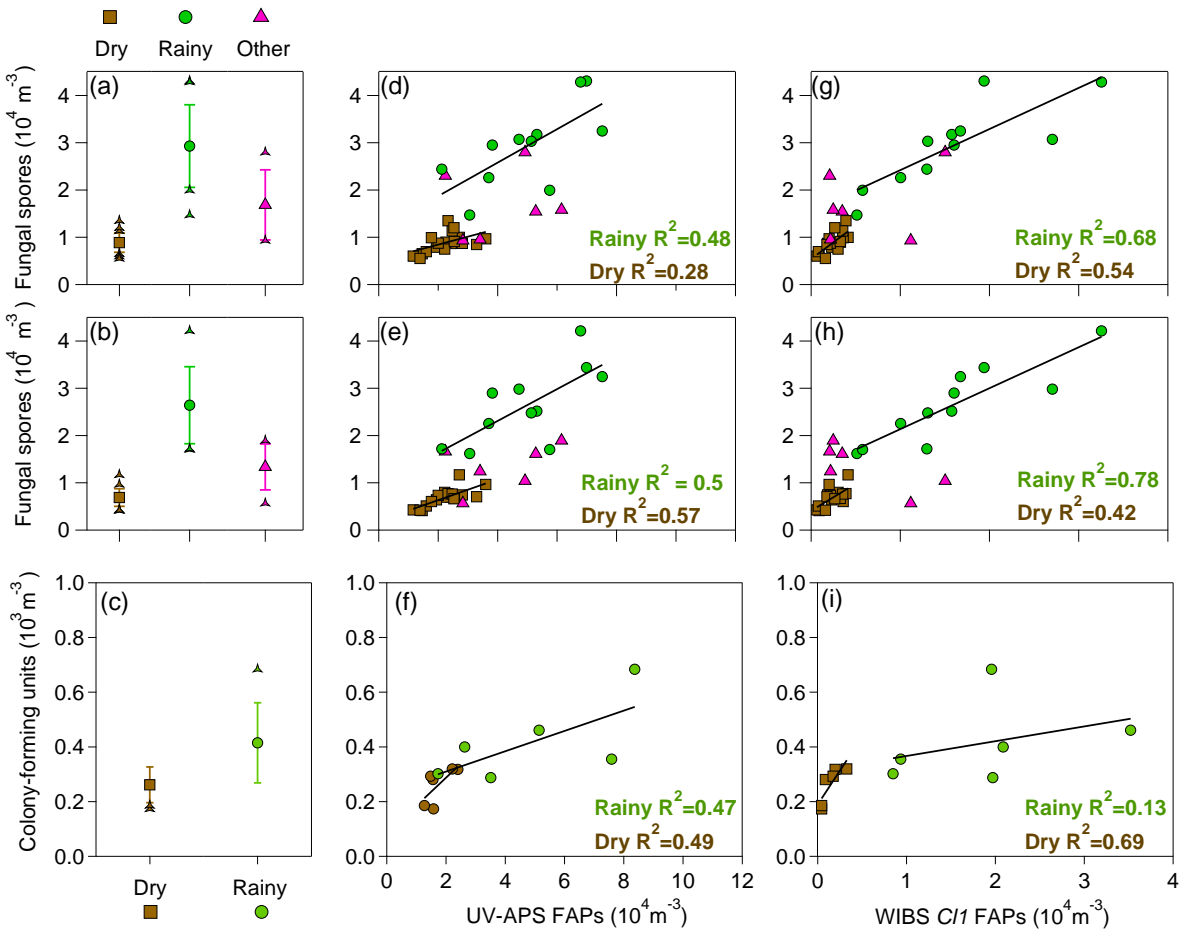

Figure 6. Estimated fungal spore number concentration, calculated using mass of arabitol and mannitol per spore reported by Bauer et al. (2008a). Estimates from arabitol (top row) and mannitol (bottom row). Average fungal spore concentration, calculated using arabitol mass (a), mannitol mass (b), and colony-forming units (c) in each wetness category. Central marker shows mean value of individual filter concentration values, bars represent standard deviation (SD) range of filter values, and individual points show outliers beyond mean \pm SD. Correlation of fungal spore number calculated from arabitol (d), mannitol (e), and colony-forming units (f) concentrations with estimated fluorescent particle mass from UV-APS. Correlation of fungal spore number calculated from arabitol (g), mannitol (h), and colony-forming unit (i) concentrations with fluorescent particle concentrations from WIBS cluster 1. $R^{2}$ value shown for each fit (right two columns). Linear fit parameters are shown in Table S3.

The first, and most important observation is that the estimated fungal spore concentration from each technique is on the same order of magnitude, $10^{4} \mathrm{~m}^{-3}$. Looking at individual correlations reveals a finer layer of detail. These results show that the number concentration of fungal spores estimated by the UV-APS is greater than the number of fungal spores estimated by the tracers, as evidenced by slope values of ca. 0.2 and 0.35 for Rainy and Dry conditions, respectively (Table S3, Fig. 6d, e). Again, this suggests that the UV-APS detects fungal spores as well as other types of fluorescent particles. The $R^{2}$ values $(\sim 0.5)$ during Rainy periods indicate that the additional source of particles detected by the UVAPS is likely to have a similar source, such as PBAPs mechanically ejected from soil and vegetative surfaces with rain splash (Huffman et al., 2013). The magnitude of the overestimation is higher during Dry periods, which would be expected because Rainy periods exhibited much higher particle number fractions associated with polyol-containing spores.

The Cl1 cluster from WIBS data shows correlations with estimated fungal spores from arabitol and mannitol that have slopes much closer to 1.0 than correlations with UV-APS number (Fig. 6g, h, Table S3). For example, the slope of the Cl1 correlations with each polyol during Rainy periods is ca. 0.87 . This suggests only a $13 \%$ difference between the spore concentration estimates from the two techniques during Rainy periods. The average number concentration of $\mathrm{Cl} 1$ during Rainy periods is $1.6 \times 10^{4}( \pm 0.8)$ spores $\mathrm{m}^{-3}$. In both cases the slopes with respect to $\mathrm{Cl} 1$ are greater than 1.0 during Dry periods, suggesting that the cluster method may be missing some fraction of weakly fluorescent particles. Huffman et al. (2012) similarly suggests that particles that are weakly fluorescent may be below the detection limit of the instrument and Healy et al. (2014) suggested that both UVAPS and WIBS-4 instruments significantly under-count the ubiquitous Cladosporium spores that are most common during dry weather and often peak in the afternoon when RH is low (De Groot, 1968; Oliveira et al., 2009). Fundamentally, however, the results from the UV-APS, and even more so the numbers reported by the clustering analysis by Crawford et al. (2015), reveal broadly similar trends with the numbers estimated from polyol-to-spore values reported by Bauer et al. (2008a).

The fungal culture samples show similar division during Rainy and Dry periods as arabitol and mannitol concentra- 
Table 4. Campaign-average fungal spore concentration and mass contribution estimated from arabitol and mannitol mass measurements. Values are mean \pm standard deviation; $n$ shows number of samples used for averaging. Fungal spore mass assumption of 33 pg spore $^{-1}$ (Bauer et al., 2008b). Total particulate matter mass calculated from UV-APS number concentration $\left(\mathrm{m}^{-3}\right)$, converted to mass over aerodynamic particle diameter range $0.5-15 \mu \mathrm{m}$ using $1.5 \mathrm{~g} \mathrm{~cm}^{-3}$ density.

\begin{tabular}{lll}
\hline \multicolumn{3}{c}{ Fungal spore number concentration $\left(\mathrm{m}^{-3}\right)$} \\
\hline Dry & $8900 \pm 2100$ & $6900 \pm 1900$ \\
& $n=18$ & $n=18$ \\
Rainy & $29300 \pm 8700$ & $26400 \pm 8100$ \\
& $n=11$ & $n=11$ \\
Other & $16900 \pm 7400$ & $13400 \pm 4900$ \\
& $n=6$ & $n=6$ \\
\hline \multirow{4}{*}{ Fungal spore mass contribution $(\%)$} \\
Rry & $4.8 \% \pm 1.43$ & $3.7 \% \pm 1.1$ \\
& $n=18$ & $n=18$ \\
Rainy & $22.9 \% \pm 8.8$ & $20.7 \% \pm 8.5$ \\
& $n=11$ & $n=11$ \\
Other & $9.8 \% \pm 7.7$ & $7.3 \% \pm 5.6$ \\
& $n=6$ & $n=6$ \\
\hline
\end{tabular}

tions (Fig. 6c), with an increase of ca. $1.6 \times$ during Rainy periods. The trend of a positive slope with respect to the UVLIF measurements is also similar between the tracer and culturing methods. In general, however, the $R^{2}$ value correlating CFU to fungal spore number calculated from the UV-LIF number is lower than between tracers and UV-LIF numbers (Table 3, Fig. S4). This is not unexpected for several reasons. First, the short sampling time of the culture samples (20 min) leads to poor-counting statistics and high number concentration variability, whereas each data point from the high-volume air samples represents a period of 4-48 h. Second, culture samplers, by their nature, only account for culturable fungal spores. It has been estimated that as low as $17 \%$ of aerosolized fungal species are culturable, and so it is expected that the CFU concentration observed is significantly less than the total airborne concentration of spores (Bridge and Spooner, 2001; Després et al., 2012). Nonetheless, the culturing analysis here supports the tracer and UVLIF analyses and the most important trends are consistent between all analysis methods. The concentration of fungal spores is higher during the Rainy periods, and there is a positive correlation between both tracer and CFU concentration and UV-LIF number.

In a pristine environment, such as the Amazon, supermicron particle mass has been found to consist of up to $85 \%$ biological material (Pöschl et al., 2010). Total particulate matter mass was calculated here from the UV-APS number concentrations $\left(\mathrm{m}^{-3}\right)$ and converted to mass for particles of aerodynamic diameter $0.5-10 \mu \mathrm{m}$. In only this case a den-

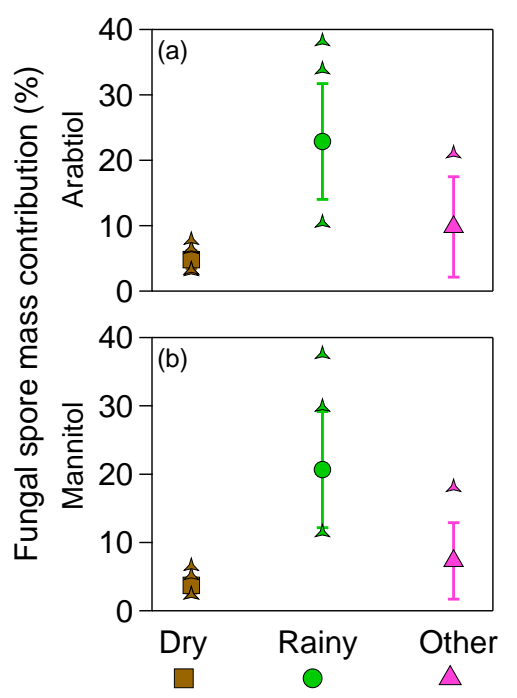

Figure 7. Estimated fraction of total aerosol mass contributed by fungal spores. Fungal spore mass concentration $\left(\mu \mathrm{g} \mathrm{m}^{-3}\right)$ calculated separately from mannitol and arabitol concentration and using average mass per spore reported by Bauer et al. (2008b). Total particulate matter mass calculated from UV-APS number concentration $\left(\mathrm{m}^{-3}\right)$ and converted to mass over aerodynamic particle diameter range $0.5-15 \mu \mathrm{m}$ using density of $1.5 \mathrm{~g} \mathrm{~cm}^{-3}$. Central marker shows mean value of individual filter concentration values, bars represent standard deviation (SD) range of filter values, and individual points show outliers beyond mean $\pm \mathrm{SD}$.

sity of $1.5 \mathrm{~g} \mathrm{~cm}^{-3}$ was utilized to calculate a first approximation of total particle mass to which all other mass measurements were compared. An average TSP mass density of $1.5 \mathrm{~g} \mathrm{~cm}^{-3}$ was utilized, because organic aerosol is typically estimated with density $<1.0 \mathrm{~g} \mathrm{~cm}^{-3}$, biological particles are often assumed to have ca. $1.0 \mathrm{~g} \mathrm{~cm}^{-3}$ density, and mineral dust particles have densities of up to ca. $3.5 \mathrm{~g} \mathrm{~cm}^{-3}$ (Dexter, 2004; Tegen and Fung, 1994). Fungal spore mass was estimated here using the fungal spore concentrations calculated from arabitol and mannitol mass (Fig. 6) and then using an estimated $33 \mathrm{pg}$ reported by Bauer et al. (2008b) as an average mass per spore. Dividing the resultant fungal spore mass by total particulate mass provides a relative mass fraction for each high-volume sample period. These calculations suggest that fungal spores represent ca. $23 \% \pm 9$ (using arabitol) or $21 \% \pm 8$ (using mannitol) of total particulate mass during Rainy periods (Table 4, Fig. 7). This represents a nearly 6-fold increase in percentage compared to Dry periods $(4.8 \% \pm 1.4$ and $3.7 \% \pm 1.1$, respectively). A similar increase during Rainy periods was also seen in the mass fraction of fungal cluster $\mathrm{Cl1}$, which represented $17 \% \pm 10$ of the particle mass during Rainy and $2 \% \pm 1$ during Dry periods (Table S4). 

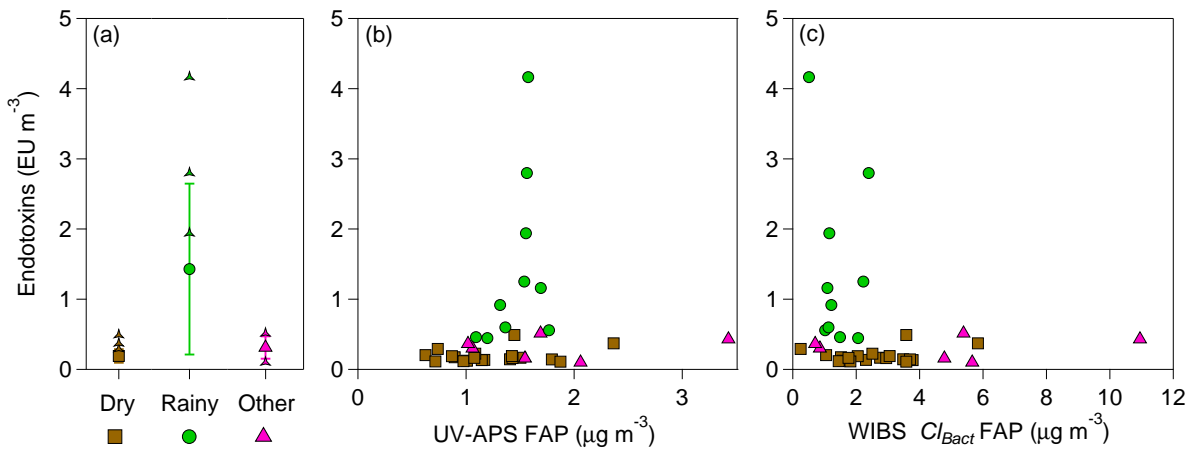

Figure 8. Endotoxin mass concentration as an approximate indicator of gram-negative bacteria concentration. (a) Averaged concentration in each wetness category. Central marker shows mean value of individual filter concentration values, bars represent standard deviation (SD) range of filter values, and individual points show outliers beyond mean $\pm \mathrm{SD}$. (b) Correlation of endotoxin mass concentration with estimated fluorescent particle mass from UV-APS. (c) Correlation of endotoxin mass concentration with estimated fluorescent particle mass summed from clusters 2, 3, and 4 from Crawford et al. (2015).

\subsection{Variations in endotoxin and glucan concentrations}

Endotoxins measured in the atmosphere are uniquely associated with gram-negative bacteria (Andreae and Crutzen, 1997). Here, we show correlations between total endotoxin mass and WIBS $\mathrm{Cl}_{\text {Bact }}$, which was assigned by Crawford et al. (2015) to be bacteria due to the small particle size $(<1 \mu \mathrm{m})$ and high correlation with rain. This assignment of particle type to this set of clusters is quite uncertain, however, and should be treated loosely. The correlation between endotoxin mass and UV-APS and the WIBS clusters was very poor, in most cases $R^{2}<0.1$ (Table 3, Fig. 8), suggesting no apparent relationship. Analysis of bacteria by both UV-LIF techniques is hampered by the fact that bacteria can be $<1 \mu \mathrm{m}$ in size and because both instruments detect particles with decreased efficiency at sizes below $0.8 \mu \mathrm{m}$. So weak correlations may not have been apparent due to reduced overlap in particle size. Despite the lack of apparent correlation between the techniques, the relatively variable endotoxin concentrations were elevated during Rainy periods, consistent with Jones and Harrison (2004), who showed that bacteria concentrations were elevated after rainy periods.

Glucans, such as $(1 \rightarrow 3)$ - $\beta$-D-glucan, are components of the cell walls of pollen, fungal spores, plant detritus, and bacteria (Chow et al., 2015b; Lee et al., 2006; Stone and Clarke, 1992). In contrast to the observed difference in endotoxin concentration during the different wetness periods, $(1 \rightarrow 3)$ $\beta$-D-glucan showed no correlations with UV-LIF concentrations (Table 3) and no differentiation during the different wetness periods.

\section{Conclusions}

Increased concentrations of fluorescent aerosol particles and ice nuclei attributed to having a biological origin were observed during and immediately after rain events throughout the BEACHON-RoMBAS study in 2011 (Huffman et al., 2013; Prenni et al., 2013; Schumacher et al., 2013). Here we expand upon the previous reports by utilizing measurements from two commercially available UV-LIF instruments, of several molecular tracers extracted from high-volume filter samples, and from a culture-based sampler in order to compare three very different methods of atmospheric fungal spore analysis. This study represents the first reported correlation of UV-LIF and molecular tracer measurements and provides an opportunity to understand how an important class of PBAPs might be influenced by periods of rainy and dry weather. We found clear patterns in the fungal molecular tracers, arabitol and mannitol, associated with Rainy conditions that are consistent with previous findings (Bauer et al., 2008a; Elbert et al., 2007; Feofilova, 2001). Fungal polyols increased 3-fold over Dry conditions during Rainy weather samples, with arabitol concentration of $35.2 \pm 10.5 \mathrm{ng} \mathrm{m}^{-3}$ and mannitol concentration of $44.9 \pm 13.8 \mathrm{ng} \mathrm{m}^{-3}$. Additionally, the very high correlation of the fungal tracers with WIBS Cl1 $\left(R^{2}>0.8\right.$ in many cases) provides support for its assignment by Crawford et al. (2015) to fungal spores. Similarly, the UV-APS correlates well with fungal tracers, however over-counts the number concentration estimated from the tracers, confirming that the UV-APS is sensitive also to other types of particles beyond fungal spores, as expected. The estimated spore count from the WIBS Cl1 concentration was within $\sim 13 \%$ of the spore count estimated by the tracer method, with concentrations ranging from 1.6 to $2.9 \times 10^{4}$ spores $\mathrm{m}^{-3}$. These values are broadly consistent with concentrations modeled by, e.g., Spracklen and Heald (2014), Hoose et al. (2010), and Hummel et al. (2015). These spore counts represent $17-23 \%$ of the total particle mass during Rainy conditions and 2-5\% during Dry conditions. Culturebased sampling also shows a similar relationship between CFU and UV-LIF concentrations and an increase of $\sim 1.6 \times$ between Dry and Rainy conditions. Despite the fact that 
the tracer and UV-LIF approaches to estimating atmospheric fungal spore concentration are fundamentally different, they provide remarkably similar estimates and temporal trends. With further improvements in instrumentation and analysis methods (e.g., advanced clustering algorithms applied to UVLIF data), the ability to reliably discriminate between PBAP types is improving. As we have shown here, this technology represents a potential for monitoring approximate fungal spore mass and for contributing improved information on fungal spore concentration to global and regional models that to this point has been lacking (Spracklen and Heald, 2014).

\section{Data availability}

Please contact the author for data used in all plots presented here.

\section{The Supplement related to this article is available online at doi:10.5194/acp-16-15165-2016-supplement.}

Acknowledgements. The BEACHON-RoMBAS campaign was partially supported by an ETBC (Emerging Topics in Biogeochemical Cycles) grant to the National Center for Atmospheric Research (NCAR), the University of Colorado, Colorado State University, and Penn State University (NSF ATM-0919189). The authors wish to thank Jose Jimenez, Douglas Day (Univ. Colorado-Boulder); Anthony Prenni, Paul DeMott, Sonia Kreidenweis, and Jessica Prenni (Colorado St. Univ.); Alex Guenther and Jim Smith (NCAR) for BEACHON-RoMBAS project organization and logistical support and the USFS, NCAR, and Richard Oakes for access to the Manitou Experimental Forest Observatory field site. Measurements of temperature, relative humidity, wind speed, and wind direction were provided by Andrew Turnipseed (NCAR) and leaf wetness and disdrometer data were provided by Dave Gochis (NCAR). Marie I. Gosselin thanks the Max Planck Society for financial support. J. Alex Huffman thanks the University of Denver for intramural funding for faculty support. The Mainz team acknowledges the Mainz Bioaerosol Laboratory (MBAL) and financial support from the Max Planck Society (MPG), the Max Planck Graduate Center with the Johannes Gutenberg University Mainz (MPGC), the Geocycles Cluster Mainz (LEC Rheinland-Pfalz), and the German Research Foundation (DFG PO1013/5-1 and FR3641/1-2, FOR 1525 INUIT). The Manchester team acknowledges funding from the UK NERC (UK-BEACHON, grant no. NE/H019049/1) for participating in the BEACHON experiment, and development support of the WIBS instruments. Manchester would also like to thank Paul Kaye, the developer of the WIBS instruments and his team at the University of Hertfordshire, for their technical support. The authors thank Cristina Ruzene, Isabell Müller-Germann, Petya Yordanova, Tobias Könemann (Max Planck Inst. For Chem.), and Nicole Savage (Univ. Denver) for technical assistance.

The article processing charges for this open-access publication were covered by the Max Planck Society.
Edited by: J. Surratt

Reviewed by: four anonymous referees

\section{References}

Allitt, U.: Airborne fungal spores and the thunderstorm of 24 June 1994, Aerobiologia, 16, 397-406, 2000.

Andreae, M. O. and Crutzen, P. J.: Atmospheric Aerosols: Biogeochemical Sources and Role in Atmospheric Chemistry, Science, 276, 1052-1058, doi:10.1126/science.276.5315.1052, 1997.

Axelsson, B.-O., Saraf, A., and Larsson, L.: Determination of ergosterol in organic dust by gas chromatography-mass spectrometry, J. Chromatogr. B, 666, 77-84, doi:10.1016/03784347(94)00553-H, 1995.

Barbaro, E., Kirchgeorg, T., Zangrando, R., Vecchiato, M., Piazza, R., Barbante, C., and Gambaro, A.: Sugars in Antarctic aerosol, Atmos. Environ., 118, 135-144, doi:10.1016/j.atmosenv.2015.07.047, 2015.

Bauer, H., Claeys, M., Vermeylen, R., Schueller, E., Weinke, G., Berger, A., and Puxbaum, H.: Arabitol and mannitol as tracers for the quantification of airborne fungal spores, Atmos. Environ., 42, 588-593, doi:10.1016/j.atmosenv.2007.10.013, 2008a.

Bauer, H., Schueller, E., Weinke, G., Berger, A., Hitzenberger, R., Marr, I. L., and Puxbaum, H.: Significant contributions of fungal spores to the organic carbon and to the aerosol mass balance of the urban atmospheric aerosol, Atmos. Environ., 42, 5542-5549, doi:10.1016/j.atmosenv.2008.03.019, 2008b.

Bigg, E. K., Soubeyrand, S., and Morris, C. E.: Persistent aftereffects of heavy rain on concentrations of ice nuclei and rainfall suggest a biological cause, Atmos. Chem. Phys., 15, 2313-2326, doi:10.5194/acp-15-2313-2015, 2015.

Bridge, P. and Spooner, B.: Soil fungi: diversity and detection, Plant Soil, 232, 147-154, 2001.

Buller, A.: Spore deposits - the number of spores, Researches on Fungi, 1, 79-88, 1909.

Burger, H.: Official Publication of American Academy of Allergy and ImmunologyBioaerosols: Prevalence and health effects in the indoor environment, J. Allergy Clin. Immun., 86, 687-701, doi:10.1016/S0091-6749(05)80170-8, 1990.

Burshtein, N., Lang-Yona, N., and Rudich, Y.: Ergosterol, arabitol and mannitol as tracers for biogenic aerosols in the eastern Mediterranean, Atmos. Chem. Phys., 11, 829-839, doi:10.5194/acp-11-829-2011, 2011.

Caseiro, A., Marr, I. L., Claeys, M., Kasper-Giebl, A., Puxbaum, H., and Pio, C. A.: Determination of saccharides in atmospheric aerosol using anion-exchange high-performance liquid chromatography and pulsed-amperometric detection, J. Chromatogr. A, 1171, 37-45, doi:10.1016/j.chroma.2007.09.038, 2007.

Cheng, J. Y. W., Hui, E. L. C., and Lau, A. P. S.: Bioactive and total endotoxins in atmospheric aerosols in the Pearl River Delta region, China, Atmos. Environ., 47, 3-11, doi:10.1016/j.atmosenv.2011.11.055, 2012.

Chow, J. C., Lowenthal, D. H., Chen, L.-W. A., Wang, X., and Watson, J. G.: Mass reconstruction methods for PM2. 5: a review, Air Quality, Atmosphere \& Health, 8, 243-263, $2015 \mathrm{a}$.

Chow, J. C., Yang, X., Wang, X., Kohl, S. D., Hurbain, P. R., Chen, L. A., and Watson, J. G.: Characterization of Ambient PM10 
Bioaerosols in a California Agricultural Town, Aerosol Air Qual. Res., 15, 1433-1447, 2015b.

Crawford, I., Robinson, N. H., Flynn, M. J., Foot, V. E., Gallagher, M. W., Huffman, J. A., Stanley, W. R., and Kaye, P. H.: Characterisation of bioaerosol emissions from a Colorado pine forest: results from the BEACHON-RoMBAS experiment, Atmos. Chem. Phys., 14, 8559-8578, doi:10.5194/acp-14-8559-2014, 2014.

Crawford, I., Ruske, S., Topping, D. O., and Gallagher, M. W.: Evaluation of hierarchical agglomerative cluster analysis methods for discrimination of primary biological aerosol, Atmos. Meas. Tech., 8, 4979-4991, doi:10.5194/amt-8-4979-2015, 2015.

Dales, R. E., Cakmak, S., Judek, S., Dann, T., Coates, F., Brook, J. R., and Burnett, R. T.: The role of fungal spores in thunderstorm asthma, Chest, 123, 745-750, 2003.

De Groot, R.: Diurnal cycles of air-borne spores produced by forest fungi, Phytopathology, 58, 1223-1229, 1968.

Deguillaume, L., Leriche, M., Amato, P., Ariya, P. A., Delort, A.M., Pöschl, U., Chaumerliac, N., Bauer, H., Flossmann, A. I., and Morris, C. E.: Microbiology and atmospheric processes: chemical interactions of primary biological aerosols, Biogeosciences, 5, 1073-1084, doi:10.5194/bg-5-1073-2008, 2008.

Després, V. R., Huffman, J. A., Burrows, S. M., Hoose, C., Safatov, A. S., Buryak, G., Frohlich-Nowoisky, J., Elbert, W., Andreae, M. O., Poschl, U., and Jaenicke, R.: Primary biological aerosol particles in the atmosphere: a review, Tellus B, 64, 15598, doi:10.3402/Tellusb.V64i0.15598, 2012.

Dexter, A.: Soil physical quality: Part I. Theory, effects of soil texture, density, and organic matter, and effects on root growth, Geoderma, 120, 201-214, 2004.

Di Filippo, P., Pomata, D., Riccardi, C., Buiarelli, F., and Perrino, C.: Fungal contribution to size-segregated aerosol measured through biomarkers, Atmos. Environ., 64, 132-140, 2013.

Douwes, J., Thorne, P., Pearce, N., and Heederik, D.: Bioaerosol health effects and exposure assessment: progress and prospects, Ann. Occup. Hyg., 47, 187-200, 2003.

Elbert, W., Taylor, P. E., Andreae, M. O., and Pöschl, U.: Contribution of fungi to primary biogenic aerosols in the atmosphere: wet and dry discharged spores, carbohydrates, and inorganic ions, Atmos. Chem. Phys., 7, 4569-4588, doi:10.5194/acp-7-4569-2007, 2007.

Faulwetter, R.: Wind-blown rain, a factor in disease dissemination, J. Agric. Res, 10, 639-648, 1917.

Feofilova, E. P.: The Kingdom Fungi: Heterogeneity of Physiological and Biochemical Properties and Relationships with Plants, Animals, and Prokaryotes (Review), Appl. Biochem. Microbiol., 37, 124-137, doi:10.1023/a:1002863311534, 2001.

Foot, V. E., Kaye, P. H., Stanley, W. R., Barrington, S. J., Gallagher, M., and Gabey, A.: Low-cost real-time multiparameter bio-aerosol sensors, 71160I-71160I-71112, SPIE Europe Security and Defence, International Society for Optics and Photonics, 2008.

Frankland, A. and Gregory, P.: Allergenic and agricultural implications of airborne ascospore concentrations from a fungus, Didymella exitialis, Nature, 245, 336-337, doi:10.1038/245336a0, 1973

Fröhlich-Nowoisky, J., Pickersgill, D. A., Després, V. R., and Pöschl, U.: High diversity of fungi in air particulate matter, P. Natl. Acad. Sci., 106, 12814-12819, 2009.
Fröhlich-Nowoisky, J., Burrows, S. M., Xie, Z., Engling, G., Solomon, P. A., Fraser, M. P., Mayol-Bracero, O. L., Artaxo, P., Begerow, D., Conrad, R., Andreae, M. O., Després, V. R., and Pöschl, U.: Biogeography in the air: fungal diversity over land and oceans, Biogeosciences, 9, 1125-1136, doi:10.5194/bg9-1125-2012, 2012.

Fröhlich-Nowoisky, J., Kampf, C. J., Weber, B., Huffman, J. A., Pöhlker, C., Andreae, M. O., Lang-Yona, N., Burrows, S. M., Gunthe, S. S., Elbert, W., Su, H., Hoor, P., Thines, E., Hoffmann, T., Després, V. R., and Pöschl, U.: Bioaerosols in the Earth System: Climate, Health, and Ecosystem Interactions, Atmos. Res., 182, 346-376, doi:10.1016/j.atmosres.2016.07.018, 2016.

Gabey, A. M., Gallagher, M. W., Whitehead, J., Dorsey, J. R., Kaye, P. H., and Stanley, W. R.: Measurements and comparison of primary biological aerosol above and below a tropical forest canopy using a dual channel fluorescence spectrometer, Atmos. Chem. Phys., 10, 4453-4466, doi:10.5194/acp-10-4453-2010, 2010.

Gilardoni, S., Vignati, E., Marmer, E., Cavalli, F., Belis, C., Gianelle, V., Loureiro, A., and Artaxo, P.: Sources of carbonaceous aerosol in the Amazon basin, Atmos. Chem. Phys., 11, 27472764, doi:10.5194/acp-11-2747-2011, 2011.

Gonçalves, F. L. T., Bauer, H., Cardoso, M. R. A., Pukinskas, S., Matos, D., Melhem, M., and Puxbaum, H.: Indoor and outdoor atmospheric fungal spores in the São Paulo metropolitan area (Brazil): species and numeric concentrations, Int. J. Biometeorol., 54, 347-355, 2010.

Graham, B., Guyon, P., Taylor, P. E., Artaxo, P., Maenhaut, W., Glovsky, M. M., Flagan, R. C., and Andreae, M. O.: Organic compounds present in the natural Amazonian aerosol: Characterization by gas chromatography-mass spectrometry, J. Geophys. Res.-Atmos., 108, 4766-4766, doi:10.1029/2003jd003990, 2003.

Gregory, P. H. and Sreeramulu, T.: Air spora of an estuary, T. Brit. Mycol. Soc., 41, 145-156, doi:10.1016/S0007-1536(58)80025X, 1958.

Haga, D., Iannone, R., Wheeler, M., Mason, R., Polishchuk, E., Fetch, T., Kamp, B., McKendry, I., and Bertram, A.: Ice nucleation properties of rust and bunt fungal spores and their transport to high altitudes, where they can cause heterogeneous freezing, J. Geophys. Res.-Atmos., 118, 7260-7272, 2013.

Hairston, P. P., Ho, J., and Quant, F. R.: Design of an instrument for real-time detection of bioaerosols using simultaneous measurement of particle aerodynamic size and intrinsic fluorescence, J. Aerosol Sci., 28, 471-482, 1997.

Heald, C. L. and Spracklen, D. V.: Atmospheric budget of primary biological aerosol particles from fungal spores, Geophys. Res. Lett., 36, L09806, doi:10.1029/2009GL037493, 2009.

Healy, D. A., Huffman, J. A., O'Connor, D. J., Pöhlker, C. Pöschl, U., and Sodeau, J. R.: Ambient measurements of biological aerosol particles near Killarney, Ireland: a comparison between real-time fluorescence and microscopy techniques, Atmos. Chem. Phys., 14, 8055-8069, doi:10.5194/acp-14-80552014, 2014.

Hernandez, M., Perring, A. E., McCabe, K., Kok, G., Granger, G., and Baumgardner, D.: Chamber catalogues of optical and fluorescent signatures distinguish bioaerosol classes, Atmos. Meas. Tech., 9, 3283-3292, doi:10.5194/amt-9-3283-2016, 2016. 
Hill, S. C., Mayo, M. W., and Chang, R. K.: Fluorescence of bacteria, pollens, and naturally occurring airborne particles: excitation/emission spectra, DTIC Document, 2009.

Hill, S. C., Pan, Y.-L., Williamson, C., Santarpia, J. L., and Hill, H. H.: Fluorescence of bioaerosols: mathematical model including primary fluorescing and absorbing molecules in bacteria, Optics Express, 21, 22285-22313, doi:10.1364/oe.21.022285, 2013.

Hill, S. C., Williamson, C. C., Doughty, D. C., Pan, Y.-L., Santarpia, J. L., and Hill, H. H.: Size-dependent fluorescence of bioaerosols: Mathematical model using fluorescing and absorbing molecules in bacteria, J. Quant. Spectrosc. Ra. Transfer, 157, 54-70, doi:10.1016/j.jqsrt.2015.01.011, 2015.

Hirst, J. and Stedman, O.: Dry liberation of fungus spores by raindrops, Microbiology, 33, 335-344, 1963.

Hoose, C., Kristjánsson, J. E., Chen, J.-P., and Hazra, A.: A Classical-Theory-Based Parameterization of Heterogeneous Ice Nucleation by Mineral Dust, Soot, and Biological Particles in a Global Climate Model, J. Atmos. Sci., 67, 2483-2503, doi:10.1175/2010JAS3425.1, 2010.

Huffman, J. A. and Santarpia, J.: Online techniques for quantification and characterization of biological aerosol, in: Microbiology of aerosols, edited by: Delort, A.-M. and Amato, P., Wiley, Hoboken, NJ, in press, 2017.

Huffman, J. A., Sinha, B., Garland, R. M., Snee-Pollmann, A., Gunthe, S. S., Artaxo, P., Martin, S. T., Andreae, M. O., and Pöschl, U.: Size distributions and temporal variations of biological aerosol particles in the Amazon rainforest characterized by microscopy and real-time UV-APS fluorescence techniques during AMAZE-08, Atmos. Chem. Phys., 12, 11997-12019, doi:10.5194/acp-12-11997-2012, 2012.

Huffman, J. A., Prenni, A. J., DeMott, P. J., Pöhlker, C., Mason, R. H., Robinson, N. H., Fröhlich-Nowoisky, J., Tobo, Y., Després, V. R., Garcia, E., Gochis, D. J., Harris, E., Müller-Germann, I., Ruzene, C., Schmer, B., Sinha, B., Day, D. A., Andreae, M. O., Jimenez, J. L., Gallagher, M., Kreidenweis, S. M., Bertram, A. K., and Pöschl, U.: High concentrations of biological aerosol particles and ice nuclei during and after rain, Atmos. Chem. Phys., 13, 6151-6164, doi:10.5194/acp-13-6151-2013, 2013.

Hummel, M., Hoose, C., Gallagher, M., Healy, D. A., Huffman, J. A., O'Connor, D., Pöschl, U., Pöhlker, C., Robinson, N. H., Schnaiter, M., Sodeau, J. R., Stengel, M., Toprak, E., and Vogel, H.: Regional-scale simulations of fungal spore aerosols using an emission parameterization adapted to local measurements of fluorescent biological aerosol particles, Atmos. Chem. Phys., 15, 6127-6146, doi:10.5194/acp-15-6127-2015, 2015.

Ingold, C. T.: Fungal spores: Their liberation and dispersal, Oxford University Press, 1971.

Jones, A. M. and Harrison, R. M.: The effects of meteorological factors on atmospheric bioaerosol concentrations - a review, Sci. Total Environ., 326, 151-180, doi:10.1016/j.scitotenv.2003.11.021, 2004.

Kaye, P., Stanley, W., Hirst, E., Foot, E., Baxter, K., and Barrington, S.: Single particle multichannel bio-aerosol fluorescence sensor, Optics Express, 13, 3583-3593, 2005.

Lau, A. P. S., Lee, A. K. Y., Chan, C. K., and Fang, M.: Ergosterol as a biomarker for the quantification of the fungal biomass in atmospheric aerosols, Atmos. Environ., 40, 249-259, 2006.
Laumbach, R. J. and Kipen, H. M.: Bioaerosols and sick building syndrome: particles, inflammation, and allergy, Curr. Oopin. Allergy Cl., 5, 135-139, 2005.

Lee, T., Grinshpun, S. A., Kim, K. Y., Iossifova, Y., Adhikari, A., and Reponen, T.: Relationship between indoor and outdoor airborne fungal spores, pollen, and $(1 \rightarrow 3)-\beta$-D-glucan in homes without visible mold growth, Aerobiologia, 22, 227-235, 2006.

Lee, T., Sullivan, A. P., Mack, L., Jimenez, J. L., Kreidenweis, S. M., Onasch, T. B., Worsnop, D. R., Malm, W., Wold, C. E., Hao, W. M., and Collett Jr., J. L.,: Chemical Smoke Marker Emissions During Flaming and Smoldering Phases of Laboratory Open Burning of Wildland Fuels, Aerosol Sci. Technol., 44, I-V, 2010.

Lewis, D. H. and Smith, D. C.: Sugar alcohols (polyols) in fungi and green plants, New Phytol., 66, 185-204, 1967.

Liang, L., Engling, G., He, K., Du, Z., Cheng, Y., and Duan, F.: Evaluation of fungal spore characteristics in Beijing, China, based on molecular tracer measurements, Environ. Res. Lett., 8, 014005, doi:10.1088/1748-9326/8/1/014005, 2013.

Lin, W.-H. and Li, C.-S.: Associations of fungal aerosols, air pollutants, and meteorological factors, Aerosol Sci. Technol., 32, 359-368, 2000.

Linneberg, A.: The increase in allergy and extended challenges, Allergy, 66, 1-3, 2011.

Madden, L.: Effects of rain on splash dispersal of fungal pathogens, Can. J. Plant Pathol., 19, 225-230, 1997.

Madelin, T.: Fungal aerosols: a review, J. Aerosol Sci., 25, 14051412, 1994.

Miller, J. D. and Young, J. C.: The use of ergosterol to measure exposure to fungal propagules in indoor air, American Industrial Hygiene Association Journal, 58, 39-43, 1997.

Morris, C. E., Sands, D. C., Glaux, C., Samsatly, J., Asaad, S., Moukahel, A. R., Gonçalves, F. L. T., and Bigg, E. K.: Urediospores of rust fungi are ice nucleation active at $>-10^{\circ} \mathrm{C}$ and harbor ice nucleation active bacteria, Atmos. Chem. Phys., 13, 4223-4233, doi:10.5194/acp-13-4223-2013, 2013.

Müllner, D.: fastcluster: fast hierarchical, agglomerative clustering routines for $\mathrm{R}$ and Python, J. Stat. Softw., 9, 1-18, doi:10.18637/jss.v053.i09, 2013.

Oliveira, M., Ribeiro, H., Delgado, J., and Abreu, I.: The effects of meteorological factors on airborne fungal spore concentration in two areas differing in urbanisation level, Int. J. Biometeorol., 53, 61-73, 2009.

Ortega, J., Turnipseed, A., Guenther, A. B., Karl, T. G., Day, D. A., Gochis, D., Huffman, J. A., Prenni, A. J., Levin, E. J. T., Kreidenweis, S. M., DeMott, P. J., Tobo, Y., Patton, E. G., Hodzic, A., Cui, Y. Y., Harley, P. C., Hornbrook, R. S., Apel, E. C., Monson, R. K., Eller, A. S. D., Greenberg, J. P., Barth, M. C., CampuzanoJost, P., Palm, B. B., Jimenez, J. L., Aiken, A. C., Dubey, M. K., Geron, C., Offenberg, J., Ryan, M. G., Fornwalt, P. J., Pryor, S. C., Keutsch, F. N., DiGangi, J. P., Chan, A. W. H., Goldstein, A. H., Wolfe, G. M., Kim, S., Kaser, L., Schnitzhofer, R., Hansel, A., Cantrell, C. A., Mauldin, R. L., and Smith, J. N.: Overview of the Manitou Experimental Forest Observatory: site description and selected science results from 2008 to 2013, Atmos. Chem. Phys., 14, 6345-6367, doi:10.5194/acp-14-6345-2014, 2014.

Perring, A., Schwarz, J., Baumgardner, D., Hernandez, M., Spracklen, D., Heald, C., Gao, R., Kok, G., McMeeking, G., and McQuaid, J.: Airborne observations of regional variation in 
fluorescent aerosol across the United States, J. Geophys. Res.Atmos., 120, 1153-1170, 2015.

Pöhlker, C., Huffman, J. A., and Pöschl, U.: Autofluorescence of atmospheric bioaerosols - fluorescent biomolecules and potential interferences, Atmos. Meas. Tech., 5, 37-71, doi:10.5194/amt-537-2012, 2012a.

Pöhlker, C., Wiedemann, K. T., Sinha, B., Shiraiwa, M., Gunthe, S. S., Smith, M., Su, H., Artaxo, P., Chen, Q., and Cheng, Y.: Biogenic potassium salt particles as seeds for secondary organic aerosol in the Amazon, Science, 337, 1075-1078, 2012 b.

Pöhlker, C., Huffman, J. A., Förster, J.-D., and Pöschl, U.: Autofluorescence of atmospheric bioaerosols: spectral fingerprints and taxonomic trends of pollen, Atmos. Meas. Tech., 6, 3369-3392, doi:10.5194/amt-6-3369-2013, 2013.

Pöschl, U. and Shiraiwa, M.: Multiphase chemistry at the atmosphere-biosphere interface influencing climate and public health in the Anthropocene, Chem. Rev., 115, 4440-4475, 2015.

Pöschl, U., Martin, S., Sinha, B., Chen, Q., Gunthe, S., Huffman, J., Borrmann, S., Farmer, D., Garland, R., and Helas, G.: Rainforest aerosols as biogenic nuclei of clouds and precipitation in the Amazon, Science, 329, 1513-1516, doi:10.1126/science.1191056, 2010.

Prenni, A. J., Tobo, Y., Garcia, E., DeMott, P. J., Huffman, J. A., McCluskey, C. S., Kreidenweis, S. M., Prenni, J. E., Pöhlker, C., and Pöschl, U.: The impact of rain on ice nuclei populations at a forested site in Colorado, Geophys. Res. Lett., 40, 227-231, doi:10.1029/2012g1053953, 2013.

Pyrri, I. and Kapsanaki-Gotsi, E.: A comparative study on the airborne fungi in Athens, Greece, by viable and non-viable sampling methods, Aerobiologia, 23, 3-15, 2007.

Rasband, W. S.: ImageJ, U.S. National Institutes of Health, Bethesda, Maryland, USA, available at: http://imagej.nih.gov/ij/, 1997-2016.

Rathnayake, C. M., Metwali, N., Baker, Z., Jayarathne, T., Kostle, P. A., Thorne, P. S., O'Shaughnessy, P. T., and Stone, E. A.: Urban enhancement of PM10 bioaerosol tracers relative to background locations in the Midwestern United States, J. Geophys. Res.-Atmos., 121, 5071-5089, 2016a.

Rathnayake, C. M., Metwali, N., Jayarathne, T., Kettler, J., Huang, Y., Thorne, P. S., O'Shaughnessy, P. T., and Stone, E. A.: Influence of Rain on the Abundance and Size Distribution of Bioaerosols, Atmos. Chem. Phys. Discuss., doi:10.5194/acp2016-622, in review, 2016b.

Robinson, N. H., Allan, J. D., Huffman, J. A., Kaye, P. H., Foot, V. E., and Gallagher, M.: Cluster analysis of WIBS single-particle bioaerosol data, Atmos. Meas. Tech., 6, 337-347, doi:10.5194/amt-6-337-2013, 2013.

Ruske, S., Topping, D. O., Foot, V. E., Kaye, P. H., Stanley, W. R., Crawford, I., Morse, A. P., and Gallagher, M. W.: Evaluation of Machine Learning Algorithms for Classification of Primary Biological Aerosol using a new UV-LIF spectrometer, Atmos. Meas. Tech. Discuss., doi:10.5194/amt-2016-214, in review, 2016.

Saari, S., Putkiranta, M., and Keskinen, J.: Fluorescence spectroscopy of atmospherically relevant bacterial and fungal spores and potential interferences, Atmos. Environ., 71, 202-209, 2013.

Saari, S., Niemi, J., Rönkkö, T., Kuuluvainen, H., Järvinen, A., Pirjola, L., Aurela, M., Hillamo, R., and Keskinen, J.: Seasonal and diurnal variations of fluorescent bioaerosol concentration and size distribution in the urban environment, Aerosol Air Qual Res., 15, 572-581, 2015.

Schauer, J. J., Rogge, W. F., Hildemann, L. M., Mazurek, M. A., Cass, G. R., and Simoneit, B. R. T.: Source apportionment of airborne particulate matter using organic compounds as tracers, Atmos. Environ., 30, 3837-3855, doi:10.1016/13522310(96)00085-4, 1996.

Schumacher, C. J., Pöhlker, C., Aalto, P., Hiltunen, V., Petäjä, T., Kulmala, M., Pöschl, U., and Huffman, J. A.: Seasonal cycles of fluorescent biological aerosol particles in boreal and semiarid forests of Finland and Colorado, Atmos. Chem. Phys., 13, 11987-12001, doi:10.5194/acp-13-11987-2013, 2013.

Sesartic, A. and Dallafior, T. N.: Global fungal spore emissions, review and synthesis of literature data, Biogeosciences, 8, 11811192, doi:10.5194/bg-8-1181-2011, 2011.

Sesartic, A., Lohmann, U., and Storelvmo, T.: Modelling the impact of fungal spore ice nuclei on clouds and precipitation, Environ. Res. Lett., 8, 014029, doi:10.1088/1748-9326/8/1/014029, 2013.

Simoneit, B. R. and Mazurek, M.: Organic tracers in ambient aerosols and rain, Aerosol Sci. Technol., 10, 267-291, 1989.

Simoneit, B. R. T., Kobayashi, M., Mochida, M., Kawamura, K., Lee, M., Lim, H.-J., Turpin, B. J., and Komazaki, Y.: Composition and major sources of organic compounds of aerosol particulate matter sampled during the ACE-Asia campaign, J. Geophys. Res.-Atmos., 109, doi:10.1029/2004JD004598, 2004.

Sodeau, J. and O'Connor, D.: Bioaerosol Monitoring of the Atmosphere for Occupational and Environmental Purposes, Comprehensive Analytical Chemistry, 73, 391-420, 2016.

Spracklen, D. V. and Heald, C. L.: The contribution of fungal spores and bacteria to regional and global aerosol number and ice nucleation immersion freezing rates, Atmos. Chem. Phys., 14, 90519059, doi:10.5194/acp-14-9051-2014, 2014.

Stone, B. and Clarke, A.: Chemistry and biology of (1, 3)-Dglucans, Victoria, Australia, La Trobe University Press, 236-239, 1992.

Taylor, P. E. and Jonsson, H.: Thunderstorm asthma, Current Allergy and Asthma Reports, 4, 409-413, 2004.

Tegen, I. and Fung, I.: Modeling of mineral dust in the atmosphere: Sources, transport, and optical thickness, J. Geophys. Res.-Atmos., 99, 22897-22914, 1994.

Tobo, Y., Prenni, A. J., DeMott, P. J., Huffman, J. A., McCluskey, C. S., Tian, G., Pöhlker, C., Pöschl, U., and Kreidenweis, S. M.: Biological aerosol particles as a key determinant of ice nuclei populations in a forest ecosystem, J. Geophys. Res.-Atmos., 118, 10100-10110, doi:10.1002/jgrd.50801, 2013.

Toprak, E. and Schnaiter, M.: Fluorescent biological aerosol particles measured with the Waveband Integrated Bioaerosol Sensor WIBS-4: laboratory tests combined with a one year field study, Atmos. Chem. Phys., 13, 225-243, doi:10.5194/acp-13225-2013, 2013.

Weete, J. D.: Sterols of the fungi: distribution and biosynthesis, Phytochemistry, 12, 1843-1864, 1973.

Womiloju, T. O., Miller, J. D., Mayer, P. M., and Brook, J. R.: Methods to determine the biological composition of particulate matter collected from outdoor air, Atmos. Environ., 37, 4335-4344, 2003.

Yang, Y., Chan, C.-Y., Tao, J., Lin, M., Engling, G., Zhang, Z., Zhang, T., and Su, L.: Observation of elevated fungal tracers due 
to biomass burning in the Sichuan Basin at Chengdu City, China, Sci. Total Environ., 431, 68-77, 2012.

Yttri, K. E., Simpson, D., Nøjgaard, J. K., Kristensen, K., Genberg, J., Stenström, K., Swietlicki, E., Hillamo, R., Aurela, M., Bauer, H., Offenberg, J. H., Jaoui, M., Dye, C., Eckhardt, S., Burkhart, J. F., Stohl, A., and Glasius, M.: Source apportionment of the summer time carbonaceous aerosol at Nordic rural background sites, Atmos. Chem. Phys., 11, 13339-13357, doi:10.5194/acp11-13339-2011, 2011a.

Yttri, K. E., Simpson, D., Stenström, K., Puxbaum, H., and Svendby, T.: Source apportionment of the carbonaceous aerosol in Norway - quantitative estimates based on ${ }^{14} \mathrm{C}$, thermal-optical and organic tracer analysis, Atmos. Chem. Phys., 11, 9375-9394, doi:10.5194/acp-11-9375-2011, 2011 b.

Yue, S., Ren, H., Fan, S., Sun, Y., Wang, Z., and Fu, P.: Springtime precipitation effects on the abundance of fluorescent biological aerosol particles and HULIS in Beijing, Scientific Reports, 6, 2016.
Zhang, T., Engling, G., Chan, C.-Y., Zhang, Y.-N., Zhang, Z.-S., Lin, M., Sang, X.-F., Li, Y. D., and Li, Y.-S.: Contribution of fungal spores to particulate matter in a tropical rainforest, Environ. Res. Lett., 5, doi:10.1088/1748-9326/5/2/024010, 2010.

Zhang, Z., Engling, G., Zhang, L., Kawamura, K., Yang, Y., Tao, J., Zhang, R., Chan, C.-Y., and Li, Y.: Significant influence of fungi on coarse carbonaceous and potassium aerosols in a tropical rainforest, Environ. Res. Lett., 10, 1-9, 2015.

Zhu, C., Kawamura, K., and Kunwar, B.: Organic tracers of primary biological aerosol particles at subtropical Okinawa Island in the western North Pacific Rim, J. Geophys. Res.-Atmos., 120, 5504 5523, doi:10.1002/2015jd023611, 2015. 